\title{
Novel and conserved miRNAs in the halophyte Suaeda maritima identified by deep sequencing and computational predictions using the ESTs of two mangrove plants
}

\author{
Sachin Ashruba Gharat ${ }^{*}$ and Birendra Prasad Shaw
}

\begin{abstract}
Background: Although miRNAs are reportedly involved in the salt stress tolerance of plants, miRNA profiling in plants has largely remained restricted to glycophytes, including certain crop species that do not exhibit any tolerance to salinity. Hence, this manuscript describes the results from the miRNA profiling of the halophyte Suaeda maritima, which is used worldwide to study salt tolerance in plants.

Results: A total of 134 conserved miRNAs were identified from unique sRNA reads, with 126 identified using miRBase 21.0 and an additional eight identified using the Plant Non-coding RNA Database. The presence of the precursors of seven conserved miRNAs was validated in S. maritima. In addition, 13 novel miRNAs were predicted using the ESTs of two mangrove plants, Rhizophora mangle and Heritiera littoralis, and the precursors of seven miRNAs were found in S. maritima. Most of the miRNAs considered for characterization were responsive to $\mathrm{NaCl}$ application, indicating their importance in the regulation of metabolic activities in plants exposed to salinity. An expression study of the novel miRNAs in plants of diverse ecological and taxonomic groups revealed that two of the miRNAs, sma-miR6 and sma-miR7, were also expressed in Oryza sativa, whereas another two, sma-miR2 and sma-miR5, were only expressed in plants growing under the influence of seawater, similar to S. maritima.

Conclusion: The distribution of conserved miRNAs among only 25 families indicated the possibility of identifying a greater number of miRNAs with increase in knowledge of the genomes of more halophytes. The expression of two novel miRNAs, sma-miR2 and sma-miR5, only in plants growing under the influence of seawater suggested their metabolic regulatory roles specific to saline environments, and such behavior might be mediated by alterations in the expression of certain genes, modifications of proteins leading to changes in their activity and production of secondary metabolites as revealed by the miRNA target predictions. Moreover, the auxin responsive factor targeted by sma-miR7 could also be involved in salt tolerance because the target is conserved between species. This study also indicated that the transcriptome of one species can be successfully used to computationally predict the miRNAs in other species, especially those that have similar metabolism, even if they are taxonomically separated.
\end{abstract}

Keywords: Sesuvium portulacastrum, miRNA, Salinity, NaCl, Abiotic stress, Halophyte, Oryza sativa

\footnotetext{
* Correspondence: sachingharat113@gmail.com

Environmental Biotechnology Laboratory, Institute of Life Sciences,

Bhubaneswar 751023, Odisha, India
} 


\section{Background}

The spatial and temporal regulation of gene expression in response to environmental cues are important factors for determining plant survival and adaptability leading to development of an ecotype [1]. Transcriptome studies have shown that plants challenged with an abiotic stress present altered expression levels of a number of genes involved in a broad spectrum of biochemical, cellular and physiological processes, including genes providing resistance to the abiotic stress [2-4]. Alterations to gene expression may occur because of regulatory mechanisms working at several levels. The two most well-known and studied categories of regulation are those involving transcription factors and small RNAs (sRNAs). While transcription factors work at the transcription level, sRNAs regulate gene expression at both the transcription and post-transcription levels. The importance of transcription factors in the regulation of gene expression and their associated mechanisms has been known since the 1980s [5-7] and can be illustrated by the presence of a massive number of transcription factor families and the extensive combinatorial control of gene expression by multiple transcription factors. However, the regulatory role of sRNAs in gene expression was only discovered two decades later after observing the reduced accumulation of gene products (mRNA) upon the introduction of dsRNA homologous to the gene into the tissue $[8,9]$. As per our current understanding, sRNAs are typified by a large and growing class of $\sim 22$-nucleotide (nt)-long noncoding RNAs that function in association with Argonaute (Ago)-family proteins [10].

In plants, sRNAs exhibit an unexpected complexity and are classified based on their biogenesis and the structure of the genomic loci from which they are transcribed [11]. At present, sRNAs are distinguished as microRNAs (miRNAs) and three classes of endogenous small interfering RNAs (siRNAs), specifically transacting siRNA (ta-siRNA), heterochromatic siRNA (hcsiRNA) and natural antisense siRNA (nat-siRNA) [11, 12]. Among these, miRNA-guided post-transcriptional gene regulation constitutes one of the most conserved and well-characterized gene regulatory mechanisms, and it is important for development, stress responses and a myriad of other biological processes in eukaryotes [11, 13, 14]. The involvement of miRNAs increases the complexity of gene regulation processes because miRNAs generally have multiple targets, including transcription factors, and transcription factors also regulate the expression of primiRNA [15]. This complexity is further increased because miRNAs have been discovered to regulate gene expression at the transcriptional level [16]. In one of the first records of miRNA involvement in transcriptional gene silencing, Bao et al. [17] showed that mutations in the Arabidopsis PHABULOSA (PHB) and PHAVOLUTA (PHV) transcription factor genes, which affect the ath-miR165/ 166 complementary site in the processed mRNAs, presented decreased methylation of the gene downstream of the complementary site compared with that of the wild type. Similarly, Kim et al. [18] reported that the expression of POLR3D (DNA-directed RNA polymerase III subunit RPC4) was negatively regulated by miR320 mediated through histone methylation. However, Place et al. [19] observed the presence of a miR373 target site in the promoters of E-cadherin and cold-shock domain-containing protein $\mathrm{C} 2$ (CSDC2), and this miRNA induced the expression of both genes. In fact, miR373 represents the first evidence that miRNAs targeting promoters can enhance the synthesis of RNA or RNA activation (RNAa) in a manner similar to that shown by small activating RNAs (saRNA). Recently, Huang et al. [20] showed that three miRNAs (miR744, miR1186 and miR466d-3p) induced the expression of Ccnb1 (Cyclin B1) in mouse cell lines. In addition, miRNAs have also been reported to induce upregulation of translation of target mRNAs [21-23], making these molecules highly versatile components of gene regulation and function.

The regulatory roles of miRNAs in biotic and abiotic responses in plants have also been suggested [11, 24-27]. Sunkar and Zhu [28] were the first to demonstrate the upregulation of miR393, miR402, miR397b and miR319c by at least one of the following stresses: drought, cold and salt. Similarly, Katiyar-Agarwal et al. [29] described a novel class of bacteria-induced sRNAs in Arabidopsis thaliana. However, although further work on miRNA responses to biotic stress in plants has been conducted, particularly for pathogen-host specificity, assessments of such responses with regard to abiotic stress have mostly considered test species that are either intolerant or naturally not tolerant to a particular type of stress. To the best of our knowledge, the current understanding of miRNA expression in halophytes, the naturally salt tolerant plants, is limited to three species: Avicennia marina [30], Salicornia europaea [27] and Salicornia brachiata [31]. Deep sRNA sequencing has only been performed for the former two species, whereas high-throughput sRNA sequencing data are available for innumerable numbers of glycophytes.

The responsiveness of most miRNAs to abiotic stresses in glycophytes has been found to be species specific rather than stress specific although they might be involved in stress tolerance [13, 24, 26, 32-34]. It may be that the miRNA-mediated regulatory requirements for stress tolerance could vary with different species. Moreover, the majority of stress-related miRNA in miRNA databases were identified in model plant species, such as Arabidopsis lyrata, A. thaliana, Brachypodium distachyon, Glycine max, Medicago truncatula, Nicotiana tabacum, Oryza sativa, Physcomitrella patens, Populus trichocarpa, Solanum tuberosum, Sorghum 
bicolor, Vitis vinifera and Zea mays, and they constitute 5380 miRNAs out of the 8455 miRNAs from 73 plant species in miRBase 21.0 (http://www.mirbase.org) [35] and 11183 miRNAs out of the 15041 miRNAs from 150 plant species in the Plant Non-coding RNA Database (PNRD) (http://structuralbiology.cau.edu.cn/PNRD/) [36]. The miRNAs identified in the halophytes $S$. brachiata and $S$. europaea have yet to be included in miRBase, whereas those identified in A. marina are only partially included.

Because of ambiguities in the available information on the miRNAs involved in tolerance to salinity, which is a serious abiotic stress affecting crops worldwide, as well as the availability of limited information regarding saltresponsive miRNAs in naturally salt-tolerant plants, the present work was conducted to identify miRNAs and their targets and study their responses to salt application in S. maritima, a halophyte that grows naturally along the seashore and has been described as a well-suited plant for studying salt stress response because of its ability to grow in the presence and absence of salt [2]. The halophyte S. maritima has been exploited worldwide for the physiological and molecular characterization of salt tolerance in plants [37-39]. Recently, the possible involvement of antioxidative machinery in salt tolerance in S. maritima was also investigated [40, 41].

The current study was also designed to explore the possibility of identifying miRNAs in S. maritima using the EST database for two mangrove plants, Rhizophora mangle and Heritiera littoralis, to establish whether the transcriptome data of one species could be utilized to identify miRNAs in other species with confidence. In the present study, seven novel salt-responsive miRNAs and several conserved miRNAs were identified and validated experimentally in test plants. This study also investigated the response of these novel miRNAs to $\mathrm{NaCl}$ application and/or their presence in taxonomically and ecologically diverse plant species, including two rice cultivars (salttolerant $O$. sativa cv. Pokkali and non-tolerant $O$. sativa cv. Badami) and several plant species growing naturally under the direct influence of seawater, such as Sesuvium portulacastrum, Cyperus arenarius, Ipomoea pes-caprae and S. maritima.

\section{Methods}

\section{Test plant species and $\mathrm{NaCl}$ application}

The seeds of $S$. maritima L. were collected from adult plants growing along a mangrove coastal belt in Bhadrak $\left(21.13^{\circ} \mathrm{N}, 86.76^{\circ} \mathrm{E}\right)$, Odisha, India. The seeds were spread on autoclaved soil in plastic pots with holes at the bottom and watered every day, alternating between $1 / 10^{\text {th }}$ Hoagland's solution and Milli-Q water. The seedlings were allowed to grow in a growth chamber maintained at $24 \pm 3{ }^{\circ} \mathrm{C}, 70-75 \%$ relative humidity, and a $14 \mathrm{~h}$ of light $\left(200 \mu \mathrm{mol} \mathrm{m}{ }^{-2} \mathrm{~s}^{-1}\right) / 10 \mathrm{~h}$ of dark cycle. After $3-4$ weeks, the seedlings were approximately $2 \mathrm{~cm}$ in height. At this stage, the seedlings were transferred to soil in plastic pots. The seedlings were allowed to acclimatize and grow for $\sim 3$ months under a natural day/night cycle in a greenhouse maintained at $24 \pm 3{ }^{\circ} \mathrm{C}$ and $70-75 \%$ relative humidity. The individual pots were watered every day, alternating between $1 / 10^{\text {th }}$ Hoagland's solution and Milli-Q water except on the penultimate day of $\mathrm{NaCl}$ application. For the $\mathrm{NaCl}$ application, $500 \mathrm{ml}$ of $85 \mathrm{mM} \mathrm{NaCl}$ prepared in 1/ $10^{\text {th }}$ strength Hoagland's solution was poured into the individual pots early in the morning. The control pots received only $1 / 10^{\text {th }}$ Hoagland's solution. After $30 \mathrm{~min}, 100 \mathrm{ml}$ of $340 \mathrm{mM} \mathrm{NaCl}$ prepared in $1 / 10^{\text {th }}$ strength Hoagland's solution was poured into the treated pots at $30 \mathrm{~min}$ intervals. Seeds of the rice cultivars O. sativa cv. Badami and cv. Pokkali were collected from the Orissa University of Agriculture and Technology (OUAT), Bhubaneswar and Central Rice Research Institute (CRRI), Cuttack, respectively, and then germinated on moist filter paper in petri dishes. The germinated seeds were grown on $1 / 10^{\text {th }}$ Hoagland's solution in $200 \mathrm{ml}$ beakers for 7 days in the greenhouse under the same conditions mentioned above. Half an hour before switching on the light, the seedlings were treated with $85 \mathrm{mM} \mathrm{NaCl}$, and then the concentration was increased to $255 \mathrm{mM}$. After $9 \mathrm{~h}$ of exposure to $\mathrm{NaCl}$, the aerial portions of the test plants were excised, preserved in liquid $\mathrm{N}_{2}$ and stored at $-80{ }^{\circ} \mathrm{C}$ until use. The treatment of all the plants continued up to $96 \mathrm{~h}$ for the measurement of leaf fluorescence.

The $\mathrm{NaCl}$ treatment concentration for the individual test plants was based on lab observations and reports that $340 \mathrm{mM} \mathrm{NaCl}$ promoted the growth of S. maritima, $255 \mathrm{mM} \mathrm{NaCl}$ exerted slight inhibitory effects on the growth of O. sativa cv. Pokkali seedlings, and $255 \mathrm{mM} \mathrm{NaCl}$ significantly inhibited the growth of $O$. sativa cv. Badami [42, 43]. However, the selection of test plants for the experiment was not only based on their level of salt tolerance. Although S. maritima grows along seashores, O. sativa cv. Pokkali, which is fairly salt-tolerant, is a cultivated rice that does not naturally grow in saline environments. However, $O$. sativa cv. Badami is a cultivated rice that is not tolerant to salt. Additional plants, specifically $S$. portulacastrum, C. arenarius and I. pes-caprae, were collected from their natural environments along the seashore. S. maritima was also collected from its natural environment for the study. Samples of these plants were immediately preserved in liquid $\mathrm{N}_{2}$ for analysis. The taxonomic details of the plants are provided in Additional file 1. 


\section{Measurement of electron transport rate}

The effect of $\mathrm{NaCl}$ on the test plants grown in the lab was studied in terms of its influence on photosynthetic electron transport in the intact leaves. The parameter was estimated from the fluorescence data obtained using a field model pulse amplitude modulated fluorometer (Hansatech, UK). Before starting the measurement, the plants were kept in the dark for $30 \mathrm{~min}$. The chlorophyll fluorescence parameters were obtained for individual leaves from S. maritima and the cultivars of O. sativa (control and treated with $\mathrm{NaCl}$ for $9 \mathrm{~h}, 24 \mathrm{~h}$ and $96 \mathrm{~h}$ ) under saturating light pulses of $>6000 \mu \mathrm{mol} \mathrm{m}{ }^{-2} \mathrm{~s}^{-1}$ and actinic light of $400 \mu \mathrm{mol} \mathrm{m} \mathrm{m}^{-2} \mathrm{~s}^{-1}$. These parameters were used to calculate relative electron transport rate (ETR), which reflects the overall photosynthetic capacity in vivo according to the equation $\mathrm{ETR}=$ ФPSII $\times$ PFDa $\times(0.5)$, where PFDa is the absorbed light (considered equivalent to the PPFD (photosynthetically active photon flux density) in $\mu \mathrm{mol} \mathrm{m} \mathrm{m}^{-2} \mathrm{~s}^{-1}$ for comparative study), ФPSII is the quantum yield of photosystem II and 0.5 is a factor that accounts for the partitioning of energy between PSII and PSI. ФPSII is given as the ratio of Fq'/Fm', where $\mathrm{Fq}^{\prime}$ is the difference in fluorescence between Fm' and F' and represent the maximal fluorescence and steady state fluorescence emissions, respectively, under actinic light [44]. The ETR was determined for five leaves from the control and $\mathrm{NaCl}$-treated plants for all exposure durations.

\section{Small RNA library construction and sequencing}

Total RNA was extracted from S. maritima tissue using TRIzol reagent (Invitrogen, USA) following the manufacturer's instructions. Small RNA libraries, one each for the control and $\mathrm{NaCl}$-treated plants, were prepared with a TruSeq Small RNA Prep Kit (Illumina, Inc.) using the Illumina TruSeq Library preparation protocol according to the manufacturer's instructions. Briefly, total RNA $(1 \mu \mathrm{g})$ was separated on a denaturing polyacrylamide gel, and sRNAs of 16-29 nt were recovered. Adaptors were ligated to each end of the isolated sRNAs, and RT reactions were used to create single-stranded cDNA. The cDNA was then PCR amplified and separated using $6 \%$ PAGE, and bands corresponding to the miRNA fragments were purified. The final library was quality checked using an Agilent Bioanalyzer DNA1000 chip. Both sRNA sequencing libraries were normalized to 2 $\mathrm{nM}$ with Tris- $\mathrm{HCl}$, denatured using $\mathrm{NaOH}$, diluted to 7 pM using pre-chilled Illumina TruSeq Hybridization Buffer and hybridized onto an Illumina Paired-End Flow cell followed by cluster amplification using an Illumina cluster station with a TruSeq Cluster Generation Kit V5.0 as per the manufacturer's instructions. Single-end sequencing of 36 nt was performed using an Illumina Genome Analyzer IIx with a TrueSeq SBS kit V5.0. Base calling and FASTQ data conversion were performed using the Illumina pipeline CASAVA 1.8 package. The deep sequencing data has been submitted as SRA file at the NCBI (BioProject ID: PRJNA293256).

\section{Small RNA bioinformatics analysis}

The raw reads were filtered to remove low-quality reads, and the reads that passed the quality filter were trimmed to remove the adaptor sequences. Selected reads of $16 \mathrm{nt}$ to 29 nt were then queried against the NCBI and Rfam databases to discard abundant non-coding RNAs (rRNA, tRNA, snRNA, and snoRNA). The remaining unique small RNA reads (16 nt to $29 \mathrm{nt}$ ) were BLASTN searched against known plant miRNAs in the miRBase 21.0 and PNRD databases to identify conserved miRNAs. Only perfectly matched reads were considered to be conserved miRNAs. To explore the occurrence of novel miRNAs, the sRNA reads were mapped on the ESTs of two mangrove plants, $R$. mangle (SRX001383) and H. littoralis (SRX001410), after de novo assembly of the raw reads available in the NCBI database (http:// www.ncbi.nlm.nih.gov/sra/?term=SRP000300), considering that genes expressed in these two plants must be qualitatively similar to $S$. maritima because of similarity in their natural habitats. The secondary structures were predicted using mfold (http://mfold.rna.albany.edu/ ?q=mfold/rna-folding-form) [45] and analyzed for stable stem-loop hairpins using criteria described in [46] and [47]. Briefly, the criteria included the following: 1) the sRNA sequence matches perfectly with the precursor sequence, 2) the mature miRNA occupies only one arm of the hairpin, 3) the mature miRNA sequence has no more than six mismatches with the sequence on the opposite arm, 4) the minimum free energy (MFE) is less than or equal to $-15 \mathrm{kcal} / \mathrm{mol}$, and 5) the minimum free energy index (MFEI) is more than 0.40 .

The presence of these precursors was verified in the ESTs of S. maritima at Bionivid, Bangalore, India, which agreed to the limited use of the transcriptome data.

\section{Northern blot analysis}

Total RNA was isolated from the tissue samples of the control plants and $340 \mathrm{mM} \mathrm{NaCl}$-treated $(9 \mathrm{~h}) \mathrm{S}$. maritima using miRNeasy mini kit (Qiagen) according to the manufacturer's instructions. For the Northern blot analysis, $10 \mu \mathrm{g}$ of total RNA was resolved on a $15 \%$ ureaPAGE gel. The electrophoresed RNA was transferred onto a nylon membrane using a Trans-Blot SD SemiDry Electrophoretic Transfer Cell (Bio-Rad). The blot was air dried and UV cross-linked at $150 \mathrm{~mJ}$ using a UV cross-linker (Hoefer ${ }^{\mathrm{Tm}}$ UVC 500 Crosslinker). Probes designed from DNA oligonucleotides complementary to the miRNA sequences (Additional file 2) were endlabeled with $\left[\gamma^{-}{ }^{32} \mathrm{P}\right] \mathrm{dATP}$ using $\mathrm{T} 4$ Polynucleotide 
Kinase (Fermentas) according to the manufacturer's instructions. The membrane was pre-hybridized for $1 \mathrm{~h}$ with hybridization buffer (Sigma), and then the labeled probe was added and allowed to hybridize for $16 \mathrm{~h}$ at $37^{\circ} \mathrm{C}$. After hybridization, the membrane was washed with $2 \mathrm{X} \mathrm{SSC}$ and $0.1 \%$ SDS at $32{ }^{\circ} \mathrm{C}$ for $15 \mathrm{~min}$ and $1 \mathrm{X}$ SSC and $0.1 \%$ SDS for $15 \mathrm{~min}$ at $37^{\circ} \mathrm{C}$. The membrane was air dried and then exposed to X-ray film. When required, the membrane was stripped, re-exposed to the X-ray film to ensure complete signal removal and reused for a second hybridization. A DNA oligonucleotide complementary to U6 snRNA was used as a probe to detect the U6 snRNA for use as an internal control.

\section{Stem-loop PCR (TaqMan miRNA assay)}

A TaqMan miRNA assay was conducted to examine the expression of novel miRNAs and several conserved miRNAs in the test species and to study the relative changes in their levels in response to $\mathrm{NaCl}$ application [48]. The TaqMan miRNA assay for the individual novel miRNAs was custom designed at Applied Biosystems (Additional file 2) and obtained as kits, each consisting of 1) miRNA-specific RT primer and 2) mixture of miRNAspecific forward and reverse primers and miRNAspecific TaqMan MGB (minor groove binder) probe. For the conserved miRNAs, the assay kits were available. Total RNA was isolated from the tissue samples of the control and $\mathrm{NaCl}$-treated plants (S. maritima, O. sativa cv. Badami, and O. sativa cv. Pokkali) and from those collected from the natural environment (S. maritima, $S$. portulacastrum, $C$. arenarius and $I$. pes-caprae) using miRNeasy mini kit (Qiagen) according to the manufacturer's instructions. To create cDNA for each TaqMan miRNA assay, 20 ng of total RNA was incubated with $0.15 \mu \mathrm{l}$ of dNTPs $(100 \mathrm{mM}), 1.5 \mu \mathrm{l}$ of $10 \mathrm{X}$ reverse tran-

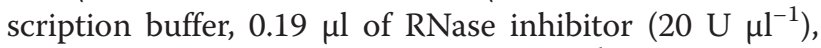
$1 \mu \mathrm{l}$ of reverse transcriptase $\left(50 \mathrm{U} \mathrm{\mu l}^{-1}\right)$, and $3 \mu \mathrm{l}$ of stem-loop reverse transcription primer (specific for individual miRNAs) in a $15 \mu \mathrm{l}$ reaction. The real-time PCR for each assay was set up as a $20 \mu \mathrm{l}$ reaction containing $10 \mu \mathrm{l}$ of TaqMan 2X Universal PCR master mix, $1 \mu \mathrm{l}$ of 20X TaqMan Assay mix that included miRNA-specific primers and TaqMan probe, and $1.33 \mu \mathrm{l}$ of cDNA. A TaqMan Assay probe for $18 \mathrm{~S}$ that was designed according to the homologous nucleotide sequences of $S$. maritima and O. sativa was used as the endogenous control for normalization of the $\mathrm{Ct}$ values of the miRNAs. The same probe also worked for the other plant species. A LightCycler 480 II (Roche) was used for the real-time PCR with the following cycling conditions: $95{ }^{\circ} \mathrm{C}$ for $10 \mathrm{~min}$ and then 40 cycles of $95{ }^{\circ} \mathrm{C}$ for $15 \mathrm{~s}$ and $60{ }^{\circ} \mathrm{C}$ for $1 \mathrm{~min}$. The TaqMan assay reactions for each miRNA in a biological sample (cDNA preparation) were performed in triplicate, and each of the PCR setups included a template-free well. Two biological samples were considered for S. maritima for the TaqMan assay, but only one sample was used for the other plants. The relative expression or abundance of miRNA in the $\mathrm{NaCl}$ treated plants relative to that in the control plants was calculated using the $2^{-\Delta \Delta C T}$ method [49]. A paired $t$-test was performed to determine significant differences $(\mathrm{P} \leq$ 0.05 ) in the abundances of miRNA in the control and $\mathrm{NaCl}$-treated plants, whereas Duncan's multiple range test was used to determine significant differences in the responses of individual miRNAs to $\mathrm{NaCl}$ among the test plants [50]. The results of the TaqMan assays for the miRNA in the plants collected from the natural environment were presented as the $\mathrm{Ct}$ values of the individual miRNAs per unit $18 \mathrm{~S} \mathrm{Ct}$ values in each respective species.

\section{Target prediction and validation}

Target prediction of the experimentally validated conserved and novel salt-responsive miRNAs was performed according to the de novo-assembled ESTs of the halophytes $R$. mangle and $H$. littoralis in the lab and using the ESTs of S. maritima at Bionivid, Bangalore, India. The target predictions were performed using psRNATarget analysis tool available online (http://plantgrn.noble.org/psRNATarget/) [51]. The maximum expectation value (measures the complementarity between small RNA sequences and its target transcripts), the hsp size (length for complementary scoring) and target accessibility were set at $3.5,17$ and 25 , respectively. The range of central mismatch leading to translation inhibition was between 9 and 11 nt. The predicted target transcript sequences were BLASTX searched at the NCBI site for annotation of their probable functions. Primer pairs (Additional file 2) were designed for several of the target sequences to examine their expression by RT-qPCR using cDNA prepared from the RNA extracted from the control and $340 \mathrm{mM}$ $\mathrm{NaCl}$-treated S. maritima. A QuantiTect Reverse Transcription Kit (Qiagen) was used to convert the RNA to cDNA. The kit provides an optimized mix of oligo-dT and random primers and gDNA Wipeout Buffer. The RT-qPCR was run on a LightCycler 480 Real-Time PCR System (Roche) using QuantiTect SYBR Green PCR Kit (Qiagen). Actin served as the reference gene. Two biological samples each from the control and $340 \mathrm{mM} \mathrm{NaCl}$-treated S. maritima were used for cDNA preparation. The PCR was performed in triplicate for each cDNA preparation. The paired $t$ test was performed to determine significant differences $(\mathrm{P} \leq 0.05)$ of expression in the genes of the control and $\mathrm{NaCl}$-treated plants. 


\section{Results}

Small RNA sequencing and data analysis

Additional file 3 shows the results from the deep sequencing of the sRNA libraries prepared with the total RNA extracted from the shoot tissue samples of young S. maritima grown in the absence of $\mathrm{NaCl}$ (control, C) and the total RNA of plants treated with $340 \mathrm{mM} \mathrm{NaCl}$ (treated, T) for $9 \mathrm{~h}$ before RNA extraction. In both cases, more than 16 million raw sRNA reads were generated on an Illumina next generation sequencing platform, and more than 2.7 million of these reads were unique. Adaptor removal and filtering of the $<16 \mathrm{nt}$ and $>30 \mathrm{nt}$ data, t/rRNA matches, etc. yielded 8981591 and 7923122 clean total reads in the control and $\mathrm{NaCl}$-treated libraries, respectively, and they could be putative miRNAs and/or siRNAs. A redundancy analysis in these sequences revealed 1715999 and 1756751 unique/non-redundant reads in the libraries prepared from the control and $\mathrm{NaCl}$-treated plants, respectively. The data showed a greater number of unique reads per unit value of the clean total reads in the $\mathrm{NaCl}$-treated library than in the control library.

\section{Identification and categorization of conserved miRNA}

Although the results indicated the presence of $>1.7$ million unique putative miRNA and/or siRNA reads in both the control and $\mathrm{NaCl}$-treated libraries (Additional file 3), only 126 were found in the miRBase 21.0 database. In addition, eight miRNAs were identified in the PNRD. Four of these were computationally predicted and the other four were found from the Illumina sequencing of the sRNAs from Setaria italica (Additional file 4). The identified 134 miRNAs were mostly 20 -nt and 21-nt in length, but their length varied from 19-nt to 22-nt (Additional file 4). These miRNAs were distributed over 68 plant species (Additional file 4), of which $A$. lyrata had maximum representation, demonstrating matches to as many as 58 miRNAs, followed by $G$. $\max , A$. thaliana, and others (Additional file 4). However, only one naturally salt-tolerant plant, Avicennia marina, a mangrove species, presented matches, and it was represented in two of the identified miRNAs, vvi-miR396b and ath-miR396b.

The miRNAs identified from both libraries were also found to be highly diverse in nature and belonged to as many as 25 families (Fig. 1). The maximum miRNA representation at up to 21 was observed in the miR166 family, and it was followed by 12 miRNAs in the miR396 family, 11 miRNAs each in the miR159 and miR319 miRNA families, and ten miRNAs in the miR156/157 family. The miR162, miR398, miR169, miR172, miR171 and miR167 miRNA families revealed five or more but less than ten representations, and the remaining miRNA families were represented by less than five miRNAs. In addition to showing the highest number of individual miRNAs, the miR166 family also showed the maximum number of combined reads/abundance (Fig. 1). The $\mathrm{NaCl}$ treatment influenced both the number of representative miRNAs and their abundance in the miRNA families (Fig. 1).

\section{Salt responsiveness of the conserved miRNAs}

To determine the salt responsiveness of the identified miRNAs, their relative abundance in the control and $\mathrm{NaCl}$-treated samples was calculated and represented as the fold change after $\mathrm{NaCl}$ treatment relative to the

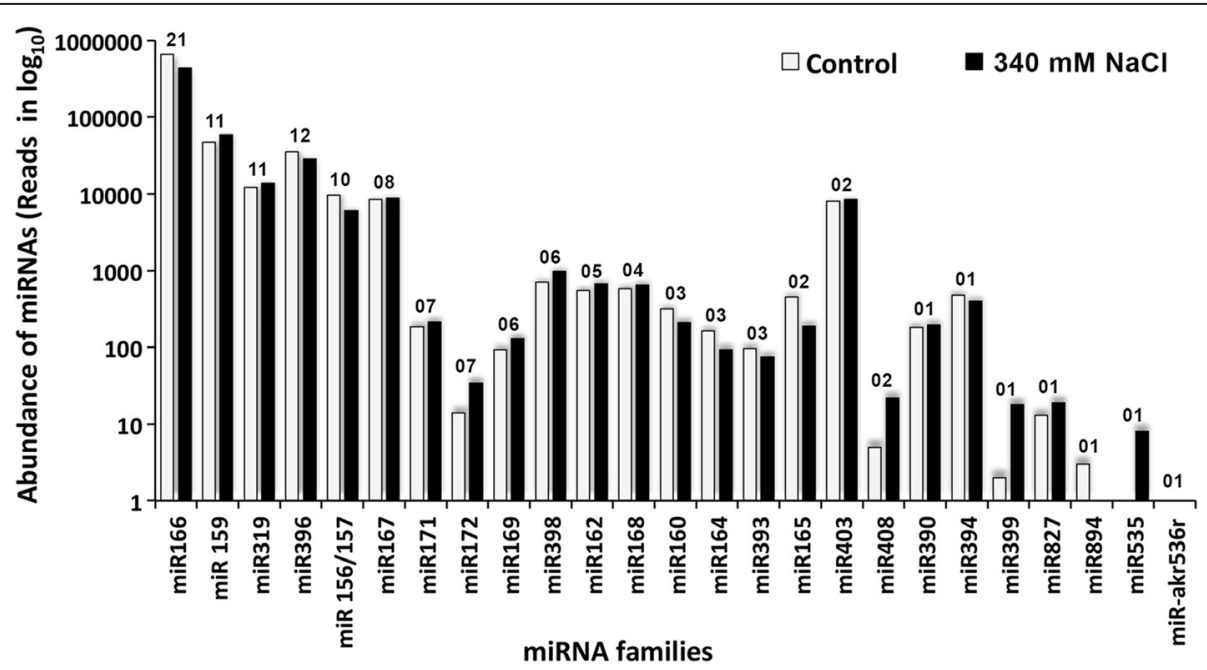

Fig. 1 Abundance of the conserved miRNAs and their distribution in the miRNA families. Abundance is expressed in terms of the number of reads in the individual miRNA families in S. maritima in the controls and after exposure to $340 \mathrm{mM} \mathrm{NaCl}$ for $9 \mathrm{~h}$. The numerical figs. at the top of the bars for the individual miRNA families are the numbers of miRNAs that were found to belong to these families out of 134 known miRNAs identified 
control level (Fig. 2). The results of only those miRNAs have been presented that either showed more than twofold change in abundance in response to $\mathrm{NaCl}$ exposure (Fig. 2a) or that showed less than twofold $\mathrm{NaCl}$-induced changes in abundance, but reported to be stress responsive (Fig. 2b). The analysis showed great variation in the responses of miRNAs after exposure of the plants to $\mathrm{NaCl}$, and the abundance of sma-miR166j decreased by

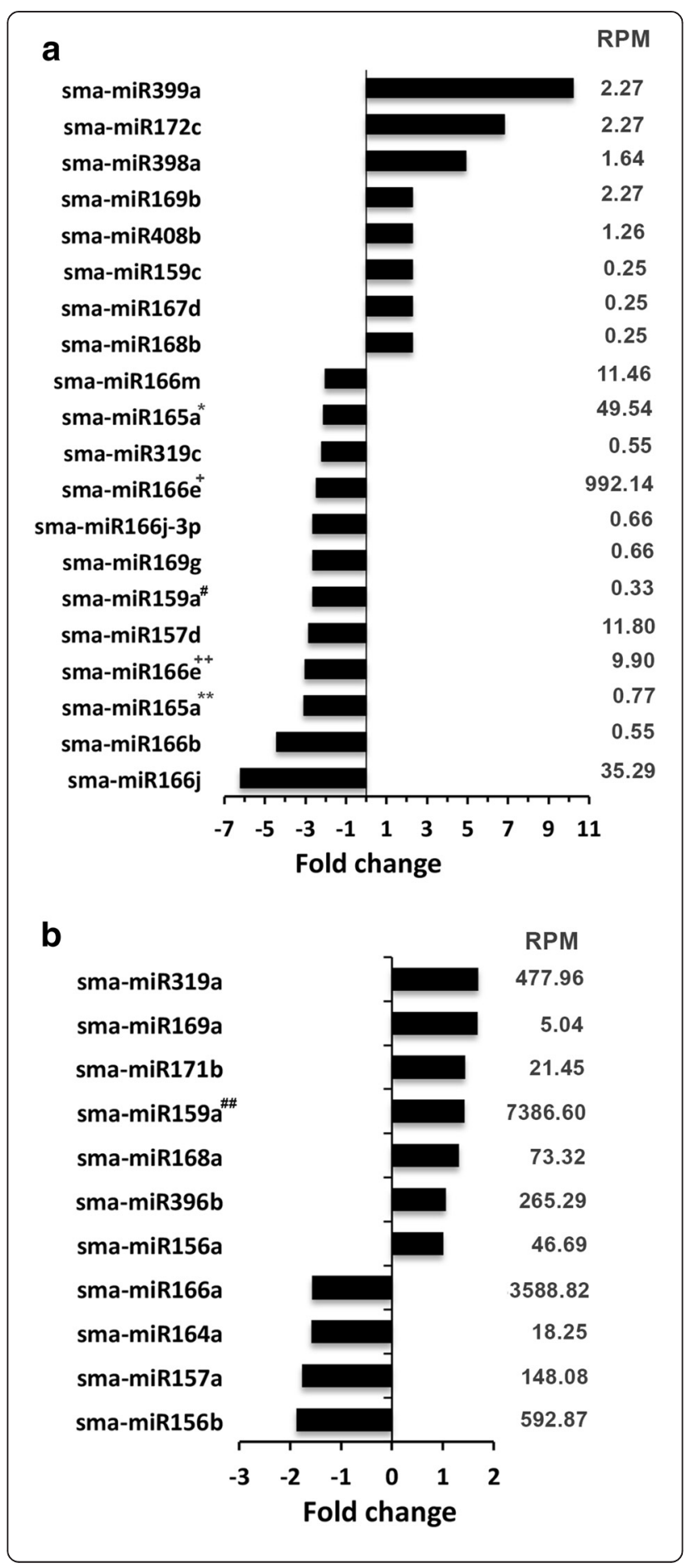

Fig. 2 Changes in the abundance of select conserved miRNAs in S. maritima in response to exposure to $340 \mathrm{mM} \mathrm{NaCl}$, which is represented as a fold change relative to the control level. a The conserved miRNAs that showed twofold or more change. $\mathbf{b}$ The conserved miRNAs reported to be salt stress responsive. Negative and positive values represent decrease and increase, respectively, in abundance of a miRNA in response to $\mathrm{NaCl}$ treatment. RPM- Reads per million; the values are of the control or treated reads, whichever the maximum. The homologous miRNAs of sma-miR165a*, smamiR165a**, sma-miR166e ${ }^{+}$, sma-miR166e ${ }^{++}$, sma-miR159a ${ }^{\#}$ and smamiR159a $a^{\# \#}$ are ath-miR165a, aly-miR165a, bdi-miR166e, osa-miR166e, pta-miR159a and ath-miR159a respectively

more than sixfold while that of sma-miR399a increased by more than tenfold in response to the $\mathrm{NaCl}$ treatment (Fig. 2a). Among the miRNAs showing less than a twofold change in response to $\mathrm{NaCl}$, the maximum upregulation was observed for sma-miR319a and the maximum downregulation was observed for sma-miR156b (Fig. 2b). In addition, most of the miRNAs that were present in high abundance with RPM (reads per million) of 50 or more showed less than a twofold change in response to salt treatment.

\section{Characterization of the conserved miRNAs}

The expression of several conserved miRNAs in S. maritima, particularly those showing high abundance in the deep sequencing results, was confirmed by identifying precursors capable of forming hairpins (Additional file 5 ) in the ESTs of the species (available at Bionivid, Bangalore) and by Northern blot hybridization (Fig. 3). These precursor ESTs could be amplified by RT-PCR (Additional file 5). The details of the precursors are provided in Additional files 4 and 6. The MFEIs of the precursors varied from 0.46 to 1.09 with an average value of 0.77 (Additional file 4). The results from the Northern blot analyses for several of the conserved miRNAs, such as sma-miR157a, sma-miR164a and sma-miR166a, indicated upregulation (Fig. 3), which was inconsistent with the results of the abundance analysis (Fig. 2). However, most of the miRNAs, such as sma-miR159a, smamiR171b and sma-miR169a, were upregulated in the Northern blot analyses in response to the $\mathrm{NaCl}$ treatment (Fig. 3), which is similar to the results of the abundance analysis (Fig. 2) except for that of the miRNA sma-miR396b, which did not present changes in its levels. Although these miRNAs have been reported to occur in a wide range of plant species encompassing monocots, dicots and pteridophytes, only one among them, sma-miR396b, has been reported from a halophyte, A. marina (Table 1). These miRNA have also been reported to be responsive to one or more abiotic stresses. In most cases, the presence of all of these miRNAs has been confirmed by sequencing, cloning and 


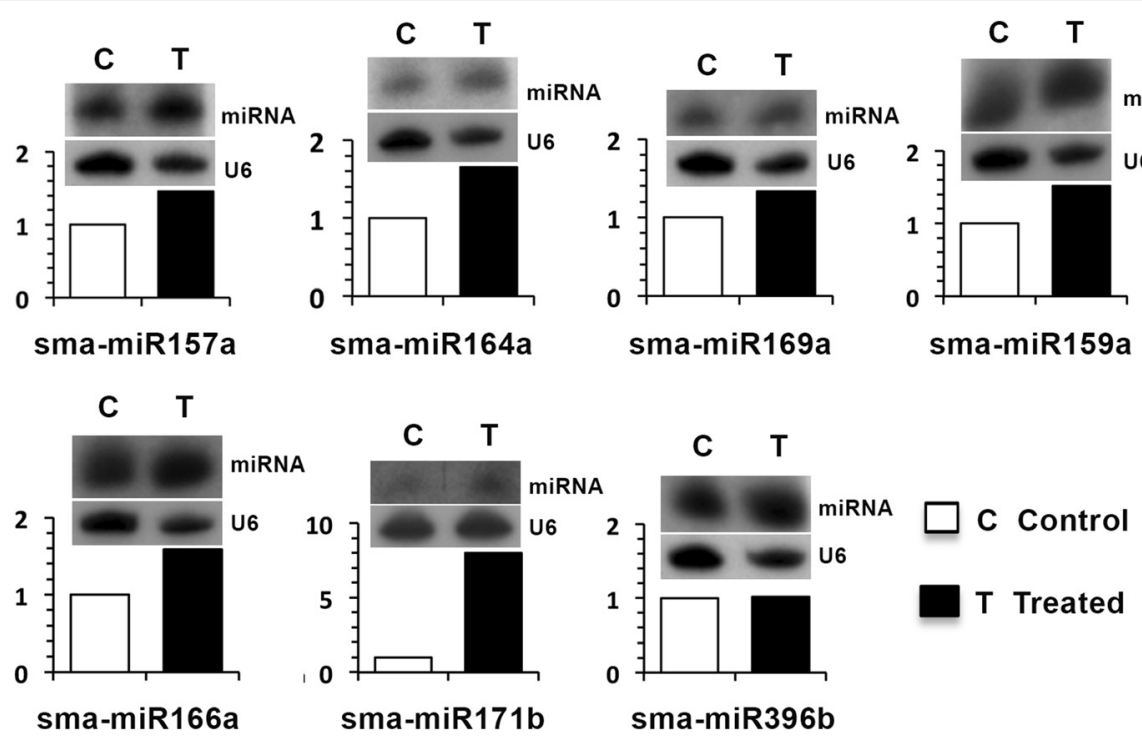

Fig. 3 Changes in the expression of select conserved miRNAs in S. maritima in response to exposure to $340 \mathrm{mM} \mathrm{NaCl}$, as determined by Northern blot analysis. The upper blot of each panel represents a hybridization signal of the anti-sense probe with a specific miRNA. U6 served as the loading control and is shown in the lower panel for the individual miRNA blot analyses. The signal intensities of U6 and miRNAs were analyzed densitometrically and plotted as a histogram representing relative changes in the hybridization intensities in the $\mathrm{NaCl}(340 \mathrm{mM})$ treated sample (filled bar) relative to the control sample (empty bar)

Northern blot analysis in the concerned species (Table 1), similar to that in the present species.

\section{Identification of novel miRNAs}

A total of 13 potential candidate miRNAs without matches in the database were identified after mapping the sRNA reads on the ESTs of $R$. mangle and $H$. littoralis and hairpin predictions (Additional files 4 and 5). However, the precursors of only seven novel miRNAs could be identified in the ESTs of S. maritima, and these precursor ESTs could also be amplified by RT-PCR (Additional file 5). The MFEs of the precursors identified in both $S$. maritima and the mangrove plants, the lengths of the pre-miRNAs, the sequences of the matured miRNAs and other details are provided in Table 2 and Additional file 4. The MFEIs of the precursors of the novel miRNAs identified from the $S$. maritima transcripts varied from 0.44 to 0.74 and had an average value of 0.59 (Additional file 4). The novel miRNAs identified showed great differences in their abundances (Fig. 4), with sma-miR6 the most abundant, followed by smamiR7. The other miRNAs were low in abundance and present in either the control (sma-miR2) or $\mathrm{NaCl}$ treated plants (sma-miR1, sma-miR3, sma-miR4 and sma-miR5).

\section{Expression analysis of selected miRNAs by quantitative PCR}

To further confirm the presence of miRNAs identified in the test species and their differential expression, a stem- loop PCR analysis (TaqMan assay) was performed using three representative conserved miRNAs and all of the novel identified miRNAs. All three conserved miRNAs showed amplification $\mathrm{Ct}$ values $<30$ and were upregulated in response to $\mathrm{NaCl}$ treatment of the plants (Fig. 5), confirming the results obtained by the Northern blot analysis (Fig. 3). High upregulation was observed for sma-miR166a, which is similar to the result obtained with Northern blotting. Among the novel miRNAs showing Ct values < 30 (Additional file 7), sma-miR2 and sma-miR7 were downregulated and sma-miR6 was upregulated (Fig. 5), which is similar to the results of the abundance analysis (Fig. 4). The stem-loop PCR although demonstrated inconsistent results with that of the abundance analysis for the sma-miR5, it generally validated the results of the abundance analysis for the miRNAs and the Northern analysis for the conserved miRNAs. A paired $t$-test revealed the significant influence of $\mathrm{NaCl}$ on the expression of all of the miRNAs assessed by the TaqMan assay except for sma-miR159a (Fig. 5). Three predicted novel miRNAs (sma-miR1, sma-miR3 and sma-miR4) were not amplified in the stem-loop PCR. The traces of progress for one representative PCR for each novel miRNA are provided in Additional file 7.

Effects of $\mathrm{NaCl}$ on the photosynthetic electron transport rates of the test plants

The influence of $\mathrm{NaCl}$ on the photosynthetic electron transport of the intact leaves of the test plants was 
Table 1 Identification and Characterization of S. maritima miRNAs that are conserved in other plants

\begin{tabular}{|c|c|c|c|c|c|}
\hline Family & miRNA & Sequence & Other plant species & Validation method & Stress response \\
\hline $\begin{array}{l}\operatorname{miR} 156 / \\
157\end{array}$ & $\begin{array}{l}\text { sma- } \\
\text { miR157a }\end{array}$ & uugacagaagauagagagcac & $\begin{array}{l}\text { aly, gma, ath, lus, ptc, mdm, mes, } \\
\text { cme, ppe, mtr, vvi, tcc, rco, bna, stu, } \\
\text { cpa, cca, sly, vun, bra, ahy, bol, gra, han }\end{array}$ & $\begin{array}{l}\text { Cloned, Northern, } \\
\text { 3' RACE, 454, MPSS, } \\
\text { Illumina }\end{array}$ & $\begin{array}{l}\text { Drought and biotic stress } \\
{[70], \text { salt stress }[60,71]}\end{array}$ \\
\hline miR159 & $\begin{array}{l}\text { sma- } \\
\text { miR159a }\end{array}$ & uuuggauugaagggagcucua & $\begin{array}{l}\text { aly, gma, ath, ptc, mes, cme, nta, ppe, } \\
\text { mtr, vvi, rco, bna, csi, cpa, sly, bra, hbr, } \\
\text { htu, ahy, pvu }\end{array}$ & $\begin{array}{l}\text { Cloned, Northern, } \\
5 \text { 'RACE, 454, MPSS, } \\
\text { Illumina }\end{array}$ & $\begin{array}{l}\text { Drought and biotic stress } \\
{[70], \text { Mechanical stress }[72],} \\
\text { biotic and drought stress } \\
{[70,73]}\end{array}$ \\
\hline $\operatorname{miR} 164$ & $\begin{array}{l}\text { sma- } \\
\text { miR164a }\end{array}$ & uggagaagcagggcacgugca & $\begin{array}{l}\text { aly, gma, ath, lus, ptc, mdm, mes, cme, } \\
\text { nta, ppe, osa, mtr, vvi, tcc, bdi, zma, rco, } \\
\text { bna, csi, sbi, cpa, ssl, ghr, tae, ctr, bra }\end{array}$ & $\begin{array}{l}\text { Cloned, Northern, } \\
\text { 5' RACE, 454, MPSS, } \\
\text { Illumina }\end{array}$ & Mechanical stress [72] \\
\hline miR166 & $\begin{array}{l}\text { sma- } \\
\text { miR166a }\end{array}$ & ucggaccaggcuucauucccc & $\begin{array}{l}\text { aly, gma, lus, mdm, mes, cme, nta, ppe, } \\
\text { vvi, tcc, bdi, rco, bna, stu, csi, aqc, cpa, sly, } \\
\text { ssl, dpr, ctr, hbr, ssp, hvu, hpe, pvu, hpa }\end{array}$ & $\begin{array}{l}\text { Cloned, Northern, } \\
5 \text { RACE, 454, MPSS, } \\
\text { Illumina }\end{array}$ & $\begin{array}{l}\text { Drought and biotic stress } \\
\text { [73], Drought stress [74], } \\
\text { dehydration stress [75], } \\
\text { cold and dehydration } \\
\text { stress [76] }\end{array}$ \\
\hline $\operatorname{miR} 169$ & $\begin{array}{l}\text { sma- } \\
\text { miR169a }\end{array}$ & cagccaaggaugacuugccga & $\begin{array}{l}\text { aly, gma, ath, lus, ptc, mes, nta, osa, mtr, } \\
\text { vvi, tcc, bdi, zma, bna, sbi, sly }\end{array}$ & $\begin{array}{l}\text { Cloned, Northern, } \\
5 \text { 'RACE, 454, MPSS, } \\
\text { Illumina }\end{array}$ & Drought stress [74] \\
\hline miR171 & $\begin{array}{l}\text { sma- } \\
\text { miR171b }\end{array}$ & ugauugagecgugccaauauc & $\begin{array}{l}\text { gma, lus, ptc, mdm, mes, cme, nta, ppe, } \\
\text { osa, mtr, vvi, tcc, bdi, zma, rco, stu, sbi, aqc, } \\
\text { cpa, sly, tae, htu, lja, crt, hvu, far, pde, hpa }\end{array}$ & By similarity & $\begin{array}{l}\text { Nutrient starvation [77], } \\
\text { mechanical stress [72], } \\
\text { drought stress [74], } \\
\text { dehydration stress [75] }\end{array}$ \\
\hline miR396 & $\begin{array}{l}\text { sma- } \\
\text { miR396b }\end{array}$ & uuccacagcuuucuugaacuu & $\begin{array}{l}\text { aly, gma, ath, lus, ptc, mdm, mes, cme, nta, } \\
\text { ppe, osa, mtr, tcc, bdi, zma, rco, bna, stu, } \\
\text { sbi, aqc, cca, pta, bgy, bcy, ama }\end{array}$ & $\begin{array}{l}\text { Northern, 5' RACE, } \\
454, \text { MPSS, PCR }\end{array}$ & $\begin{array}{l}\text { Nutrient starvation }[77], \\
\text { drought and biotic } \\
\text { stress [70], drought } \\
\text { stress [74], salt stress }[30,60]\end{array}$ \\
\hline
\end{tabular}

aly Arabidopsis lyrata, gma Glycine max, ath Arabidopsis thaliana, lus Linum usitatissimum, ptc Populus trichocarpa, mdm Malus domestica, mes Manihot esculenta, cme Cucumis melo, nta Nicotiana tabacum, ppe Prunus persica, osa Oryza sativa, mtr Medicago truncatula, vvi Vitis vinifera, tcc Theobroma cacao, bdi Brachypodium distachyon, zma Zea mays, rco Ricinus communis, bna Brassica napus, stu Solanum tuberosum, csi Citrus sinensis, sbi Sorghum bicolor, aqc Aquilegia caerulea, cpa Carica papaya, cca Cynara cardunculus, sly Solanum lycopersicum, vun Vigna unguiculata, ssl Salvia sclarea, ghr Gossypium hirsutum, tae Triticum aestivum, dpr Digitalis purpurea, aau Acacia auriculiformis, ctr Citrus trifoliate, bra Brassica rapa, hbr Hevea brasiliensis, ssp Saccharum ssp., htu Helianthus tuberosus, lja Lotus japonicas, ccl Citrus clementine, crt Citrus reticulate, smo Selaginella moellendorffii, ahy Arachis hypogaea, hvu Hordeum vulgare, bol Brassica oleracea, amg Acacia mangium, hpe Helianthus petiolaris, pta Pinus taeda, far Festuca arundinacea, pvu Phaseolus vulgaris, gra Gossypium raimondii, pde Pinus densata, hpa Helianthus paradoxus, bgy Bruguiera gymnorhiza, bcy Bruguiera cylindrical, han Helianthus annuus, har Helianthus argophyllus, ama Avicennia marina

assessed because photosynthesis is a metabolic activity unique to plants, and it is widely influenced by environmental conditions. An analysis of the photosynthetic electron transport rate (ETR) revealed that $\mathrm{NaCl}$ only produced significant effects in the rice cultivars, and the ETRs of both Badami and Pokkali decreased significantly during all $\mathrm{NaCl}$ treatment periods (Additional file 8). However, the effects were more drastic in Badami than in Pokkali, particularly during the early periods $(9 \mathrm{~h}$ and $24 \mathrm{~h}$ ) of exposure as observed from the ETR values presented as the percent of control in the inset (Additional file 8 ). The halophyte $S$. maritima did not show significant changes of ETR in response to $\mathrm{NaCl}$, even after a long period (96 h) of exposure.

\section{Analysis of the presence of the novel miRNAs in other plant species}

The novel miRNAs showing $\mathrm{Ct}$ values $<30$ in $\mathrm{S}$. maritima were evaluated for their presence in the salttolerant Pokkali and intolerant Badami cultivars. Only two miRNAs, sma-miR6 and sma-miR7, showed amplification ( $\mathrm{Ct} \sim 30$ or less) in the two rice cultivars
(Additional file 7). However, their response to the $\mathrm{NaCl}$ applications was found to differ significantly among the species (Fig. 6). While the expression of sma-miR7 exhibited downregulation in S. maritima, its expression increased in the rice cultivars in response to $\mathrm{NaCl}$, and the upregulation was more pronounced in Badami compared to that in Pokkali. Compared with sma-miR7, sma-miR6 was upregulated in all three test plants, with O. sativa $\mathrm{cv}$. Pokkali showing significantly greater upregulation compared with the other two plants. To determine why only sma-miR6 and sma-miR7 and not smamiR2 and sma-miR5 was expressed in the rice cultivars, these sequences were BLASTN searched in the rice databases, and matches were found for the former two sequences with two ESTs (Additional file 4: gi|88967261 and gi|88475521) but not for the latter sequences. Although they were not observed in miRBase, these two ESTs formed the required hairpin structure for Dicer action (Additional file 5) and could be miRNA precursors.

A TaqMan assay conducted for the above novel miRNAs in S. portulacastrum, which was collected from the natural habitat of $S$. maritima, showed amplification of 
Table 2 Novel miRNAs predicted through bioinformatics approach

\begin{tabular}{|c|c|c|c|c|c|}
\hline miRNAs & Sequence $\left(5^{\prime}-3^{\prime}\right)$ & $\begin{array}{l}\mathrm{LM} \\
\text { (nt) }\end{array}$ & $\begin{array}{l}\text { Precursor accession } \\
\text { (R. mangle } \\
\text { H. littoralis } \\
\text { S. maritima) }\end{array}$ & $\begin{array}{l}\text { LP } \\
\text { (nt) }\end{array}$ & $\begin{array}{l}\text { MFE } \\
(\mathrm{Kcal} / \mathrm{mol})\end{array}$ \\
\hline \multirow[t]{3}{*}{ sma-miR1 } & AAUAGGUACUGUAACUGGUAUU & 22 & SRX001383.5101 & 126 & -37.8 \\
\hline & & & NP & - & - \\
\hline & & & S.maritima380087 & 85 & -15.60 \\
\hline \multirow[t]{3}{*}{ sma-miR2 } & AGGGACCAGGAGAUUGGAUC ${ }^{\mathrm{a}}$ & 20 & SRX001383.146244 & 75 & -19.0 \\
\hline & & & NP & - & - \\
\hline & & & S.maritima 40845 & 73 & -15.20 \\
\hline \multirow[t]{3}{*}{ sma-miR3 } & CGGAAUAUGGUAAAGUAGCUC & 21 & SRX001383.195972 & 70 & -19.7 \\
\hline & & & NP & - & - \\
\hline & & & S.maritima1868968 & 70 & -20.10 \\
\hline \multirow[t]{3}{*}{ sma-miR4 } & CGUGGAUGUUCUUAUUUGGAC & 21 & SRX001383.88652 & 116 & -30.4 \\
\hline & & & SRX001410.01205 & 141 & -30.53 \\
\hline & & & S.maritima 870097 & 115 & -29.0 \\
\hline \multirow[t]{3}{*}{ sma-miR5 } & CUUGGUAUGGAAGUUAUGCAUG ${ }^{a}$ & 22 & SRX001383.176415 & 71 & -19.7 \\
\hline & & & NP & - & - \\
\hline & & & S.maritima37179 & 69 & -20.10 \\
\hline \multirow[t]{3}{*}{ sma-miR6 } & GCAUGGCUGUCGUCAGCUCGUG & 22 & SRX001383.110283 & 67 & -33.5 \\
\hline & & & NP & - & - \\
\hline & & & S.maritima40845 & 89 & -21.60 \\
\hline \multirow[t]{3}{*}{ sma-miR7 } & UUUUCUUGACCUUGUAAGACC & 21 & SRX001383.115761 & 90 & -40.8 \\
\hline & & & NP & - & - \\
\hline & & & S.maritima39969 & 134 & -28.73 \\
\hline
\end{tabular}

Prediction was done after alignment of the putative miRNA sequences with the ESTs of the mangrove plants $R$. mangle and $H$. littoralis available at NCBI database and then with ESTs of S. maritima at Bionivid, Bangalore, India. SRX001383 and SRX001410 are the accession numbers of $R$. mangle and $H$. littolalis, respectivey in NCBI database. $L M$ mature miRNA length, $L P$ precursor length, MFE minimum free energy, NP precursor not present

${ }^{a}$ mark against a sequence indicates the presence of miRNA*

b see Additional file 4 for sequences and other details

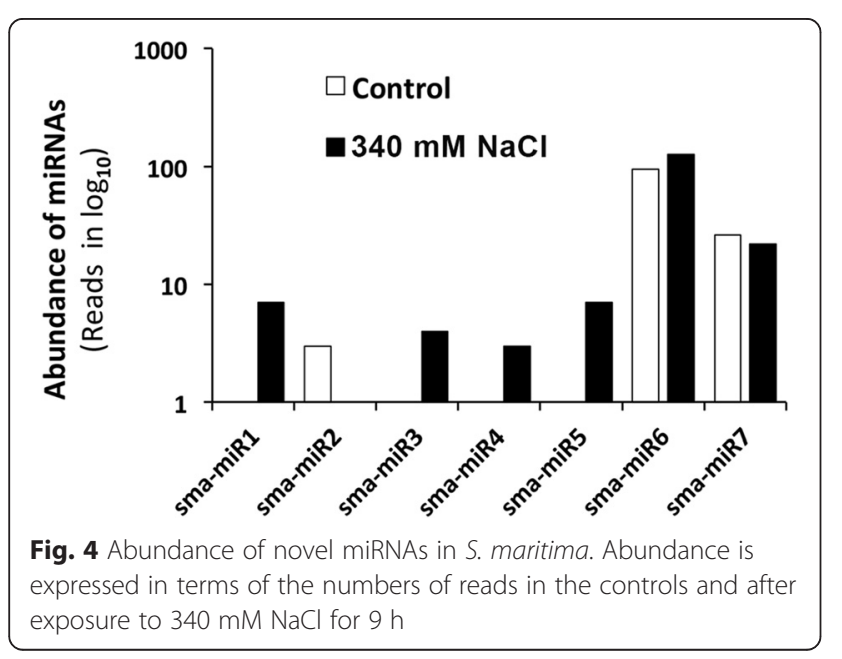

all of the miRNAs that were expressed in S. maritima, including sma-miR2 and sma-miR5, which were not expressed in the rice cultivars (Additional files 7 and 9A). The expression of sma-miR2 and sma-miR5 was further verified in two additional plant species, $I$. pes-caprae and $C$. arenarius, which grow under the influence of seawater, as well as in S. maritima collected from its natural habitat. All of the species demonstrated amplification of the two miRNAs (Additional file 9A). Normalization of the Ct values for the amplification of sma-miR2 and sma-miR5 to the per-unit $18 \mathrm{~S} \mathrm{Ct}$ values in the individual plant species revealed that the abundances of these two miRNAs were in general similar in all four species collected from the natural environment, with $C$. arenarius showing the lowest abundance and I. pes-caprae showing the maximum abundance (Additional file 9B). 


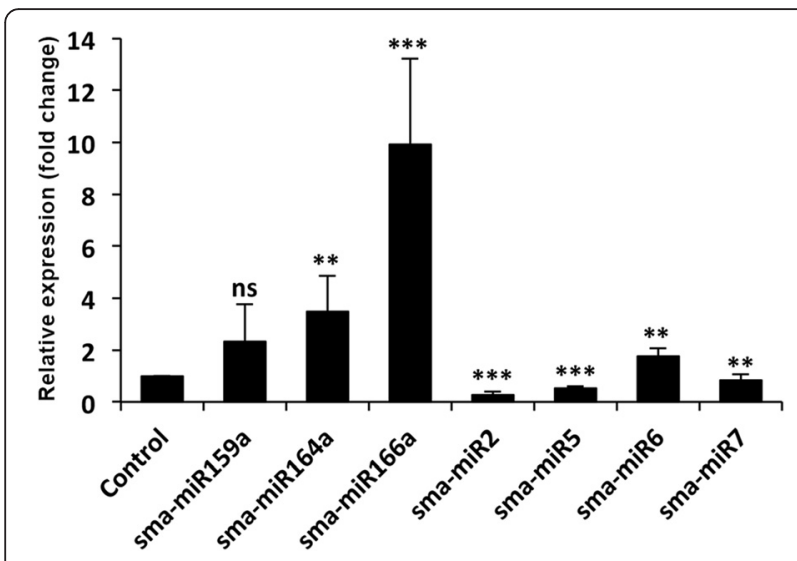

Fig. 5 Changes in the expression of select miRNAs in S. maritima in response to exposure to $340 \mathrm{mM} \mathrm{NaCl}$ as determined by stem-loop PCR. The bars for the individual miRNAs represent fold changes in their expression in response to $340 \mathrm{mM} \mathrm{NaCl}$ treatment relative to the mean expression level of the control plants. The data are the mean \pm SD of six independent estimations. Asterisks in the individual columns indicate that $\mathrm{NaCl}$-responsive changes in the expression of the respective miRNAs differed significantly from the control expression level at $p \leq 0.05\left(^{*}\right), p \leq 0.01\left(^{* *}\right)$, or $p \leq 0.001\left(^{* *}\right)$. ns $=$ not significant

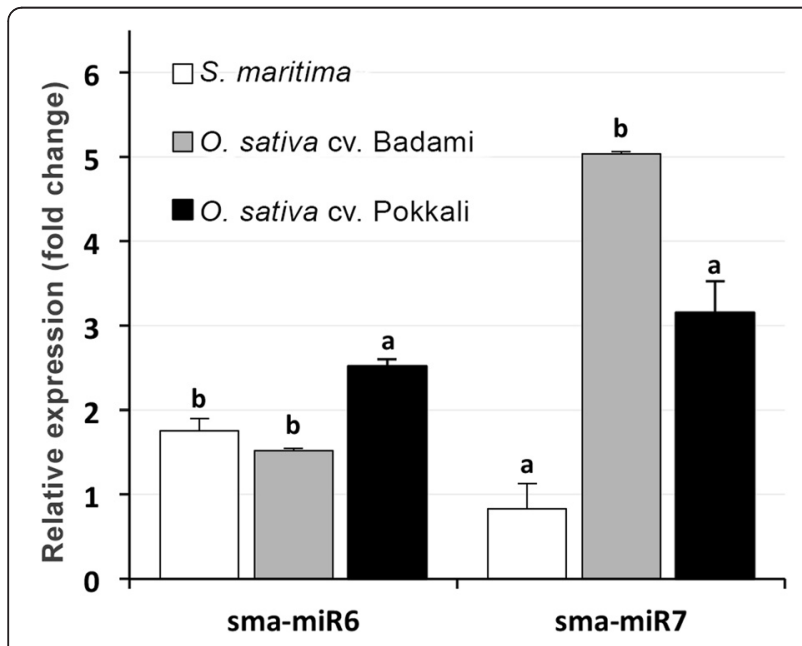

Fig. 6 Changes in the expression of sma-miR6 and sma-miR7 in the test plants in response to their exposure to $255 \mathrm{mM} \mathrm{NaCl}$ (O. sativa cv. Badami/Pokkali) or $340 \mathrm{mM} \mathrm{NaCl}$ (S. maritima) for 9 h. The bars for the individual miRNAs represent fold changes in their expression in the three test plants in response to $\mathrm{NaCl}$ treatment relative to the mean expression level in the control plants. The data are the mean \pm SD of six independent estimations for S. maritima and 3 independent estimations for the other plants. Variations in the expression of the individual miRNAs in the four plants resulting from $\mathrm{NaCl}$ treatment were statistically analyzed with an 'F' test and Duncan's multiple range test. The mean fold change in the expression of an miRNA (bars) of individual species marked with at least one common letter do not differ significantly at $p \leq 0.05$
Target prediction of miRNAs and study of their expression by qRT-PCR

To understand the biological role of the novel/conserved miRNAs expressed in $S$. maritima as determined by stem-loop PCR or Northern blotting, their putative target genes were searched using the psRNATarget tool. Table 3 shows the putative targets for each miRNA along with other information, such as the miRNA/ mRNA pairing, target description and inhibition type (cleavage/translation). Sequences of the target ESTs of both $S$. maritima and the mangrove plants are provided in Additional file 10. Most of the miRNAs targeted more than one gene product, many of which encoded hypothetical and putative uncharacterized proteins. The conserved miRNAs for which the precursors were identified in $S$. maritima and the mangrove plants targeted proteins, such as the F-box family protein, homeoboxleucine zipper, dnaJ, scarecrow-like protein and growthregulating factor (GRF) in S. maritima. In the mangrove plants, the targeted proteins were different from those in S. maritima, such as p-ATPase family transporter, RNA helicase, rhodanese-like domain protein, etc. The only target of common function in S. maritima and the mangrove plants was an F-box protein targeted by sma-miR159a. The conserved miRNAs that presented precursors only in $S$. maritima also targeted proteins such as lipid phosphate phosphatase, squamosa promoter binding-like protein, F-box protein, ubiquitinconjugating enzyme 1 and G3BP-like protein. Among the known proteins, the novel miRNAs targeted proteins such as serine/threonine kinase, DEAD-box ATP-dependent RNA helicase, auxin response factor and vacuolar protein sorting associated protein in $S$. maritima. The targets of these miRNAs in the mangrove plants were also primarily proteins with regulatory functions (Table 3). These included serine/ threonine kinase, which was targeted by sma-miR5, and auxin response factor and vacuolar protein sorting associated protein, which were targeted by smamiR7.

Changes in the expression of most of the target mRNAs of miRNA that presented precursors in $S$. maritima were verified by RT-qPCR in the plants grown in the presence and absence of $340 \mathrm{mM} \mathrm{NaCl}$. The expression of the targets of the conserved miRNAs in responses to $\mathrm{NaCl}$ exhibited varied results so far as expression of these miRNAs are concerned. Most of the targets, such as the F-box protein and zinc finger $\mathrm{CCCH}$ domain proteins, G3BP and F-box family protein member, homeobox-leucine zipper protein and scarecrow transcription factor protein, were downregulated in response to the $\mathrm{NaCl}$ application (Fig. 7) in agreement of the $\mathrm{NaCl}$-induced upregulation of the miRNAs smamiR159a, sma-miR157a, sma-miR166a and sma-miR171b 
Table 3 Targets of the novel/conserved miRNAs that expressed in S. maritima

\begin{tabular}{|c|c|c|c|c|}
\hline \multirow[t]{2}{*}{ miRNAs } & S. maritima target accession ${ }^{\mathrm{a}} /$ & $\begin{array}{l}\text { Inhibition } \\
\text { type/ }\end{array}$ & $\begin{array}{l}\text { R. mangle target accession }{ }^{\mathrm{a}} / \text { Target } \\
\text { description }\end{array}$ & $\begin{array}{l}\text { Inhibition } \\
\text { type/ }\end{array}$ \\
\hline & Target description & $\begin{array}{l}\text { miRNA-mRNA } \\
\text { pairing }\end{array}$ & $\begin{array}{l}\text { H. littoralis target accession }{ }^{\mathrm{a}} / \text { Target } \\
\text { description }\end{array}$ & $\begin{array}{l}\text { miRNA-mRNA } \\
\text { pairing }\end{array}$ \\
\hline \multicolumn{5}{|c|}{ Novel miRNAs with precursors identified in both S. maritima and mangrove plants } \\
\hline \multirow[t]{4}{*}{ sma-miR2 } & S.maritima26422/ & Cleavage/ & SRX001383.184716/ & Cleavage/ \\
\hline & $\begin{array}{l}\text { Uncharacterized protein LOC104902506 } \\
\text { isoform X1 [B. vulgaris subsp. vulgaris] }\end{array}$ & $\ldots \ldots \ldots \ldots . . \cdots . . .:$. & Hypothetical protein [C. wallichii] & 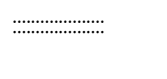 \\
\hline & S.maritima1694886/ & Cleavage/ & SRX001383.195417/ & Cleavage/ \\
\hline & 4-coumarate-CoA ligase-like 7 [E. grandis] & $: \cdots \ldots \ldots \ldots \ldots$ & $\begin{array}{l}\text { Transcriptional corepressor/coregulator } \\
\text { seuss-like }[P \text {. trichocarpa] }\end{array}$ & $\ldots . . . \cdots \ldots \ldots . . . . . .:$ \\
\hline \multirow[t]{8}{*}{ sma-miR5 } & S.maritima155512/ & Cleavage/ & SRX001383.67404/ & Cleavage/ \\
\hline & $\begin{array}{l}\text { Uncharacterized protein At4g38062 } \\
\text { [B. vulgaris subsp. vulgaris] }\end{array}$ & 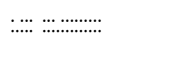 & $\begin{array}{l}\text { E3 ubiquitin-protein ligase MBR2 [P. } \\
\text { euphratica] }\end{array}$ & $\ldots \ldots \ldots \ldots \ldots . . . . .:$ \\
\hline & S.maritima714933/ & Cleavage/ & SRX001383.163041/ & Cleavage/ \\
\hline & $\begin{array}{l}\text { Serine/threonine-protein kinase PRP4 } \\
\text { homolog isoform X3 [A. pisum] }\end{array}$ & $\ldots \ldots \ldots \ldots \ldots$ & $\begin{array}{l}\text { Serine/threonine-protein kinase } \mathrm{TAO} 3 \\
{[\text { T. cacao] }}\end{array}$ & 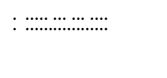 \\
\hline & & & SRX001410.05634/ & Cleavage/ \\
\hline & & & $\begin{array}{l}\text { Serine/threonine-protein kinase ATG1 } \\
\text { [G. arboreum] }\end{array}$ & $\cdots \cdots \cdots \cdots \cdots \cdots$ \\
\hline & S.maritima37141/ & Translation/ & & \\
\hline & $\begin{array}{l}\text { DEAD-box ATP-dependent RNA helicase } 58 \\
\text { chloroplastic isoform X1 [B. vulgaris subsp. vulgaris] }\end{array}$ & $:: \cdots \ldots .: \cdots \ldots \ldots .:$. & & \\
\hline \multirow[t]{4}{*}{ sma-miR6 } & S.maritima26981/ & Cleavage/ & SRX001383.21117/ & Translation/ \\
\hline & $\begin{array}{l}\text { Uncharacterized protein LOC104904783 isoform } \\
\text { X2 [B. vulgaris subsp. vulgaris] }\end{array}$ & $\ldots: \cdots \cdots \cdots \cdots \cdots: . .$. & Hypothetical protein [H. bilis] & 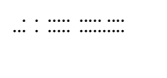 \\
\hline & S.maritima41280/ & Cleavage/ & & \\
\hline & Hypothetical protein (mitochondrion) [V. faba] & 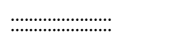 & & \\
\hline \multirow[t]{8}{*}{ sma-miR7 } & S.maritima7497/ & Translation/ & SRX001383.178145/ & Cleavage/ \\
\hline & Uncharacterized protein LOC100160261 [A. pisum] & $\ldots \ldots \ldots . . . \cdots \ldots . . .:$ & $\begin{array}{l}\text { Hypothetical protein DICPUDRAFT_75074 } \\
\text { [D. purpureum] }\end{array}$ & 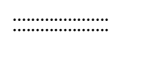 \\
\hline & S.maritima41831/ & Cleavage/ & SRX001383.116751/ & Cleavage/ \\
\hline & Auxin response factor 3 isoform $X 2[B$. vulgaris & 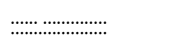 & Auxin response factor 4 [M. notabilis] & 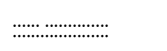 \\
\hline & subsp. vulgaris] & & SRX001410.09075/ & Cleavage/ \\
\hline & & & $\begin{array}{l}\text { Auxin response factor } 4 \text { isoform } 2 \\
{[\text { T. cacao }]}\end{array}$ & 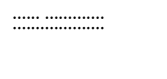 \\
\hline & S.maritima39489/ & Translation/ & SRX001383.156526/ & Translation/ \\
\hline & $\begin{array}{l}\text { Vacuolar protein sorting-associated protein } 26 \mathrm{~A} \\
\text { [B. vulgaris subsp. vulgaris] }\end{array}$ & $\ldots . .: \ldots: \ldots \ldots . . . .:$ & $\begin{array}{l}\text { Vacuolar protein sorting-associated protein } \\
\text { 26B-like [C. sativa] }\end{array}$ & $\ldots \ldots: \cdots: \cdots \cdots \ldots . . .:$ \\
\hline \multicolumn{5}{|c|}{ Conserved miRNAs with precursors identified in both S. maritima and mangrove plants } \\
\hline \multirow{8}{*}{$\begin{array}{l}\text { sma- } \\
\text { miR159a }\end{array}$} & S.maritima41732/ & Cleavage/ & SRX001383.120796/ & Cleavage/ \\
\hline & $\begin{array}{l}\text { Uncharacterized protein LOC104883236 isoform } \\
\text { X1 [B. vulgaris subsp. vulgaris] }\end{array}$ & $\ldots \ldots . . \cdots . . . . . . . . .:$ & $\begin{array}{l}\text { Hypothetical protein TRIUR3_29875 } \\
\text { [T. urartu] }\end{array}$ & 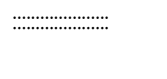 \\
\hline & S.maritima43555/ & Cleavage/ & SRX001383.174703/ & Cleavage/ \\
\hline & $\begin{array}{l}\text { Uncharacterized protein LOC104908454 } \\
\text { [B. vulgaris subsp. vulgaris] }\end{array}$ & $\ldots \ldots . . . . . . . . . .:::$ & $\begin{array}{l}\text { Conserved hypothetical protein } \\
{[R . \text { communis }]}\end{array}$ & $: \ldots \ldots . . . . . . . . . . . . . . . . . .$. \\
\hline & S.maritima36986/ & Cleavage/ & SRX001383.35722/ & Translation/ \\
\hline & F-box family protein [S. vulgaris] & $\because: \ldots \ldots \ldots \ldots . . .:$ & F-box protein [M. notabilis] & $\ldots \ldots \ldots . . . \cdots \cdots . . .:$ \\
\hline & S.maritima44432/ & Cleavage/ & SRX001383.108393/ & Cleavage/ \\
\hline & & $\ldots \ldots . . . \cdots: \ldots . . . . .:$ & & 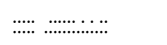 \\
\hline
\end{tabular}


Table 3 Targets of the novel/conserved miRNAs that expressed in S. maritima (Continued)

\begin{tabular}{|c|c|c|c|c|}
\hline & $\begin{array}{l}\text { Zinc finger CCCH domain-containing protein } 5 \\
\text { isoform X2 [B. vulgaris subsp. vulgaris }]\end{array}$ & & $\begin{array}{l}\text { Double-stranded RNA-binding protein } 2 \\
{[M \text {. notabilis }]}\end{array}$ & \\
\hline \multirow{4}{*}{$\begin{array}{l}\text { sma- } \\
\text { miR166a }\end{array}$} & S.maritima19497/ & Cleavage/ & SRX001383.65087/ & Cleavage/ \\
\hline & $\begin{array}{l}\text { Uncharacterized protein LOC104904626 } \\
\text { [B. vulgaris subsp. vulgaris] }\end{array}$ & $\ldots \ldots . . . . . . . . . . .: .:$ & $\begin{array}{l}\text { P-ATPase family transporter: calcium ion } \\
\text { [O. lucimarinus CCE9901] }\end{array}$ & 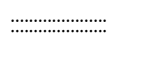 \\
\hline & S.maritima32700/ & Cleavage/ & & \\
\hline & $\begin{array}{l}\text { Homeobox-leucine zipper protein REVOLUTA-like } \\
\text { [B. vulgaris subsp. vulgaris] }\end{array}$ & 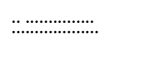 & & \\
\hline \multirow{4}{*}{$\begin{array}{l}\text { sma- } \\
\text { miR171b }\end{array}$} & S.maritima13778/ & Cleavage/ & SRX001383.169033/ & Translation/ \\
\hline & $\begin{array}{l}\text { F-box/kelch-repeat protein At3g23880-like isoform } \\
\text { X1 [B. vulgaris subsp. Vulgaris] }\end{array}$ & 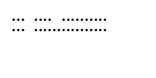 & RNA helicase 36, partial [D. oppositifolia] & $\ldots \ldots .::: \cdots \cdots \cdots:$ \\
\hline & S.maritima44824/ & Cleavage/ & & \\
\hline & $\begin{array}{l}\text { Scarecrow-like protein } 6 \text { isoform } X 1 \\
\text { [B. vulgaris subsp. vulgaris] }\end{array}$ & 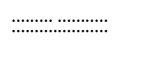 & & \\
\hline \multirow{6}{*}{$\begin{array}{l}\text { sma- } \\
\text { miR396b }\end{array}$} & S.maritima38649/ & Translation/ & SRX001383.11076/ & Cleavage/ \\
\hline & dnaJ protein ERDJ3A [B. vulgaris subsp. vulgaris] & …....................: & $\begin{array}{l}\text { Rhodanese-like domain-containing } \\
\text { protein } 14 \text {, chloroplastic [V. vinifera] }\end{array}$ & $\ldots \ldots .::: \ldots \ldots \ldots . . . . .:$ \\
\hline & S.maritima27747/ & Cleavage/ & SRX001383.145227/ & Cleavage/ \\
\hline & $\begin{array}{l}\text { Growth-regulating factor 2-like } \\
\text { [B. vulgaris subsp. vulgaris] }\end{array}$ & $\ldots \ldots \ldots \ldots . . . \cdots \cdots: .:$ & $\begin{array}{l}\text { Hypothetical protein PHAVU_009G048400g } \\
\text { [P. vulgaris] }\end{array}$ & 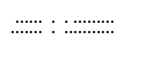 \\
\hline & S.maritima36182/ & Translation/ & SRX001383.205893/ & Cleavage/ \\
\hline & $\begin{array}{l}\text { CRS2-associated factor 2, chloroplastic } \\
\text { [B. vulgaris subsp. vulgaris] }\end{array}$ & $\because \cdots \ldots \ldots \ldots \ldots . \cdots:$ & $\begin{array}{l}\text { ABC transporter } \mathrm{F} \text { family member } 5[\mathrm{M} \text {. } \\
\text { notabilis }]\end{array}$ & $\ldots \ldots::: \cdots \ldots \ldots \ldots .:$ \\
\hline \multicolumn{5}{|c|}{ Conserved miRNAs with precursors identified only in S. maritima } \\
\hline \multirow{2}{*}{$\begin{array}{l}\text { sma- } \\
\text { miR169ab }\end{array}$} & S.maritima467708/ & Cleavage/ & & \\
\hline & $\begin{array}{l}\text { Oxysterol-binding protein-related protein } 4 \text { C-like [B. vulgaris } \\
\text { subsp. vulgaris] }\end{array}$ & $\ldots \ldots \ldots \ldots \ldots \ldots \ldots . . . .:$ & & \\
\hline \multirow{4}{*}{$\begin{array}{l}\text { sma- } \\
\text { miR164ab }\end{array}$} & S.maritima27444/ & Cleavage/ & & \\
\hline & $\begin{array}{l}\text { Uncharacterized proteinLOC104894828 } \\
\text { [B. vulgaris subsp. vulgaris]) }\end{array}$ & 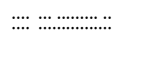 & & \\
\hline & S.maritima37419/ & Translation/ & & \\
\hline & $\begin{array}{l}\text { Lipid phosphate phosphatase delta } \\
\text { [B. vulgaris subsp. vulgaris] }\end{array}$ & 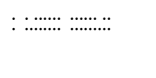 & & \\
\hline \multirow{10}{*}{$\begin{array}{l}\text { sma- } \\
\text { miR157ab }\end{array}$} & S.maritima347871/ & Cleavage/ & & \\
\hline & $\begin{array}{l}\text { Squamosa promoter-binding-like protein } 3 \\
\text { [P. euphratica] }\end{array}$ & 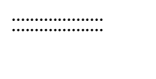 & & \\
\hline & S.maritima95321/ & Cleavage/ & & \\
\hline & Hypothetical proteinPRUPE_ppa003644mg [P. persica] & 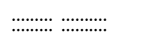 & & \\
\hline & S.maritima700613/ & Cleavage/ & & \\
\hline & $\begin{array}{l}\text { Putative F-box/kelch-repeat proteinAt } 4 \mathrm{~g} 12810 \\
\text { [B. vulgaris subsp. vulgaris] }\end{array}$ & $\ldots \ldots \ldots \ldots \ldots: \cdots: \ldots$ & & \\
\hline & S.maritima34755/ & Cleavage/ & & \\
\hline & $\begin{array}{l}\text { Ubiquitin-fold modifier-conjugating enzyme } 1 \\
\text { [B. vulgaris subsp. vulgaris] }\end{array}$ & $\ldots \ldots \ldots \ldots . . . . . . . . .:$ & & \\
\hline & S.maritima15309/ & Cleavage/ & & \\
\hline & $\begin{array}{l}\text { Putative G3BP-like protein isoform X2 } \\
\text { [B. vulgaris subsp. vulgaris] }\end{array}$ & $\ldots \ldots::: \cdots \ldots \ldots .: .:$ & & \\
\hline
\end{tabular}

The targets were identified in S. maritima, and also in Rhizophora mangle and Heritiera littoralis, the mangrove plants as the ESTs of these plants were used initially for identification of the novel miRNAs in S. maritima. SRX001383 and SRX001410 are the accession numbers of R. mangle and H. littolalis, respectivey in

NCBI database

${ }^{\mathrm{a}}$ For sequence please see Additional file 10

${ }^{\mathrm{b}}$ Precursor not identified in the mangrove plants $\mathrm{R}$. mangle and $\mathrm{H}$. littoralis 


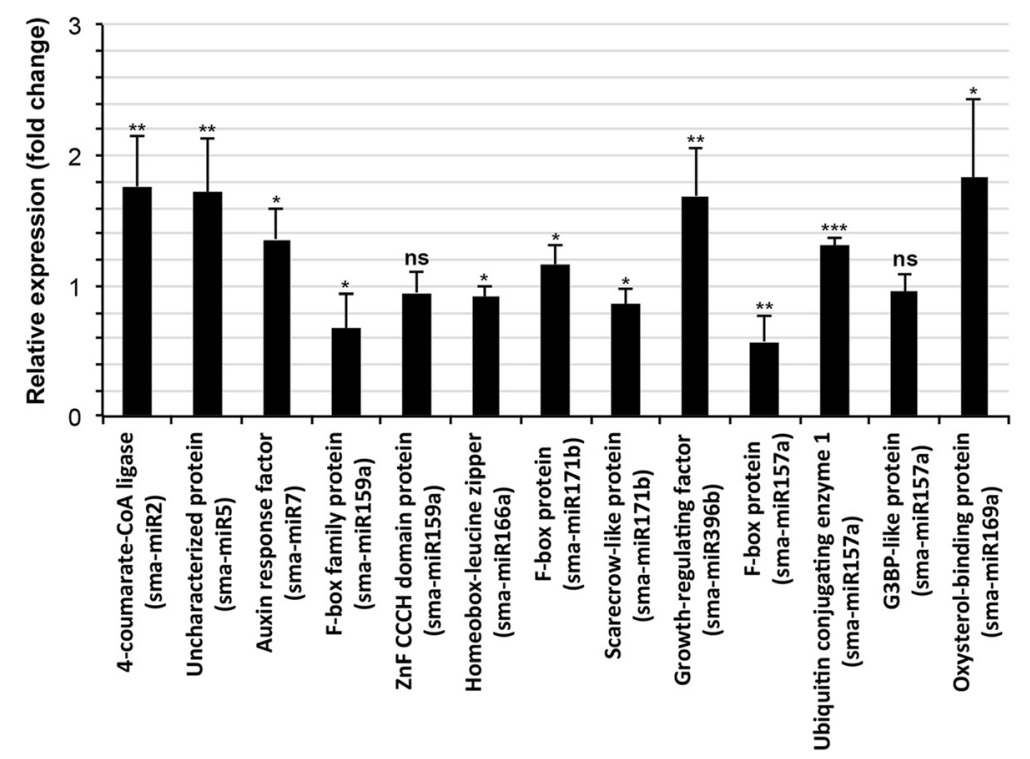

Fig. 7 Fold changes in the expression of the S. maritima transcripts targeted by the miRNAs identified in the plant after exposure to $340 \mathrm{mM}$ $\mathrm{NaCl}$ for $9 \mathrm{~h}$. The data are the mean \pm SD of six independent estimations. The values less than one represent decreases, and values more than one represent increases in the expression/abundance of the target mRNAs in the NaCl-treated plants relative to the non-treated (control) plants. The details regarding the statistical significance are as in Fig. 5

targeting them, respectively (Fig. 3). However, despite $\mathrm{NaCl}$-induced upregulation of the miRNAs sma-miR171b, sma-miR396b, sma-miR157a and sma-miR169a (Fig. 3), several of their targets were also upregulated, such as Fbox protein, GRF protein, ubiquitin conjugating enzyme and oxysterol-binding protein, respectively (Fig. 7), although these were predicted to be cleaved by their respective miRNAs (Table 3). The putative targets of all of the novel tested miRNAs (sma-miR2, sma-miR5 and smamiR7) were upregulated (Fig. 7), i.e., opposite to and in agreement with the changes in expression for the miRNAs (Fig. 5) in response to $\mathrm{NaCl}$ application.

\section{Discussion}

The identification of 134 conserved miRNAs (Fig. 1, Additional file 4) from nearly 17 million total reads (Additional file 3) in the current study is comparable to the identification of 115 conserved miRNAs from nearly 15 million reads in Cunninghamia lanceolata [47] and 210 conserved miRNAs from nearly 13 million total reads in S. europaea [27]. Most of the miRNAs identified belonged to the glycophytes such as A. lyrata, $A$. thaliana, G. max, O. sativa, P. trichocarpa, Z. mays and additional species for which the miRNA database is relatively large compared to the other plant species, suggesting the need to create miRNA and EST databases containing as many diverse groups of plant species as possible. The family diversity of miRNAs (Fig. 1) was similar to those reported in the halophytes such as Avicennia marina (193 conserved miRNAs distributed to 36 families) and S. europaea (210 conserved miRNAs distributed to 51 families), with miRNA to miRNA family ratios of $\sim 5.3$ and $\sim 4.1$, respectively $[27,30]$. In contrast, studies have shown much lower miRNA to miRNA family ratios in a range from 1.5 to 2.0 [52-56] for terrestrial plants other than halophytes. $\mathrm{NaCl}$-induced changes observed in the miRNA abundance in several miRNA families, particularly miR172, miR408, miR399, miR166, miR165 and miR535 (Fig. 1), is indicative of an altered metabolism in the test plant in the presence of salt, which was also observed in other studies, including halophytes and non-halophytes [27, 57].

The expression of several of the miRNAs such as miR166b, miR166e, and miR166m that exhibited saltinduced decreases in abundance in S. maritima (Fig. 2a) revealed increases in abundance in rice in response to salt treatment [58]. The reverse was true for other miRNAs, such as miR156a, miR159a, miR159c, miR168a, miR169a, miR169b, miR171b, miR172c, miR319a and miR398a (Fig. 2a, b) [58]. However, the expression levels of at least nine out of the 12 miRNAs found common in S. maritima and S. europaea [27] were comparable, with five (miR166a, miR164a, miR165a, miR166e, miR165a) showing downregulation and four (miR168b, miR169a, miR171b, miR396b) showing upregulation in both of the species. These observations suggested that the response 
of miRNAs to environmental change might differ with the plant species and that the level of difference would depend on the difference in their metabolism.

None of the novel miRNAs identified in S. maritima was identical to those identified in the halophytes $S$. europaea [27], S. brachiata [31] and A. marina [30], suggesting that the database of plant miRNAs is not yet saturated and that there is a need for further miRNA identification in more halophytes. However, the unavailability of genome/transcriptome information often limits such attempts. To overcome this disadvantage, Khraiwesh et al. [30] used the Mangrove Transcriptome Database (MTDB - http://mangrove.illinois.edu), whereas Singh and Jha [31] relied on the genome databases of species other than $S$. brachiata at NCBI. In fact, identification of the precursors of as many as seven novel miRNAs in S. maritima out of the 13 novel miRNAs identified using the ESTs of $R$. mangle and $H$. littoralis that met all the criteria (Table 2, Additional files 4 and 5) revealed that the ESTs of one plant species can be used in the computational predictions of miRNAs in another species, even taxonomically separated species, if they were derived from similar habitats. However, metabolism may be more important than habitat for determining similarities in the miRNAomes of two species because while all seven miRNA precursors in $S$. maritima were also present in $R$. mangle and both species accumulated high levels of $\mathrm{Na}^{+}$in their tissues [42, 59], only one of the precursors (sma-mir4) was present in $H$. littoralis, which accumulated low amounts of $\mathrm{Na}^{+}$in its tissues [59].

Most of the novel miRNAs identified were low in abundance (Fig. 4) and expressed only in response to $\mathrm{NaCl}$ (sma-miR1, -miR3, -miR4 and -miR5), unlike the conserved miRNAs. Feng et al. [27] described the lowabundance novel miRNAs in $S$. europaea that were expressed only in the salt-treated plants as speciesspecific miRNAs that could be important determinants of salt tolerance in the plant.

The influence of $\mathrm{NaCl}$ on the expression levels of miRNAs considered for Northern analysis (Fig. 3) has been reported to vary with species $[24,32,60]$, indicating a species-specific response of these miRNAs. However, because of the presence of these miRNAs in a wide taxonomic group of plant species and their responsiveness to a wide range of abiotic stresses (Table 1), their involvement in protecting plants against stress cannot be ruled out. Similarly, the salt responsiveness of the novel miRNAs, particularly of sma-miR2 and sma-miR7 showing downregulation in response to the $\mathrm{NaCl}$ treatment (Fig. 5), indicates that their metabolic functions are important for salt tolerance in the plant. A significant decrease in sma-miR7 expression in S. maritima showed no changes in ETR, whereas significant increases in the
miRNA expression level in the rice cultivars showing decreases in ETR in response to $\mathrm{NaCl}$ (Fig. 6, Additional file 8) provide circumstantial evidence of involvement of sma-miR7 in salt tolerance.

Most of the targets of the conserved miRNAs were downregulated after $\mathrm{NaCl}$ treatment (Fig. 7), which is consistent with the increased expression of the miRNAs after $\mathrm{NaCl}$ treatment, except for that of sma-miR396b (Fig. 3). The decrease in the expression of at least a few of the targets might be important in the context of salt tolerance. For example, the decrease in the cellular level of lipid phosphate phosphatase (LPP) might lead to acceleration of the phosphorylation signaling [61], which, in turn, could function to accelerate biochemical processes linked to salt tolerance. Similarly, the decreases in the cellular levels of ubiquitin-conjugating enzyme (E2) and F-box proteins might function to slow the degradation process of the cellular proteins [62-64] associated with salt tolerance in the plant. Hence, the upregulation of these miRNAs in response to $\mathrm{NaCl}$ application could be of great ecological significance in terms of adaptations of S. maritima to $\mathrm{NaCl}$.

Functional annotation of the targets of the novel miRNAs (Table 3), most of which were upregulated (Fig. 7), revealed that these targets and the associated miRNAs could be important for plant adaptations to adverse environments, a possibility that could be particularly true for sma-miR7, which was downregulated in S. maritima and upregulated in the rice cultivars (Fig. 6), and targeted ARF family proteins in S. maritima, $R$. mangle and $H$. littoralis (Table 3). Although the reports of involvement of auxins in salt resistance in plants are contradictory [65], their involvement is supported by the greater expression of sma-miR7 in the salt-sensitive Badami compared with that of the moderately salt tolerant Pokkali in response to $\mathrm{NaCl}$ application, along with the salt-induced downregulation of sma-miR2 targeting SEUSS-LIKE (SLK) protein in $R$. mangle, which is required for a proper response to the phytohormone auxin [66]. Moreover, the downregulation of seu-miR160 and seu-miR5 targeting ARF genes in S. europaea in response to $\mathrm{NaCl}$ application [27] further supports a possible role for auxin in salt tolerance in plants.

The possible involvement of sma-miR7 in salt resistance is further emphasized by the occurrence of another common target of the miRNA in S. maritima and $R$. mangle/H. littoralis, the vacuolar protein sortingassociated protein (Table 3), a constituent of ESCRTs (Endosomal Sorting Complexes Required for Transport), which are involved in mono-ubiquitination mediated endocytic trafficking of plasma membrane proteins to the vacuole followed by lysosomal degradation [67]. Moreover, this miRNA also targets the RING finger protein E3 ligase (Table 3), which serves as a unit of the 
ubiquitin/26S proteasome system. The biological role of the ubiquitin/26S proteasome system has been investigated in relation to the abiotic stress tolerance of plants and has been found to be a positive regulator of stress tolerance [63]. The suppression of the expression of the miRNA (seu-miR396h/I) that targets ubiquitin-specific proteases (UBPs) in S. europaea also strongly suggests a possible role for the ubiquitin/26S proteasome system in salt tolerance in plants [27]. Nevertheless, the activity of both plasma membrane proteins and cytosolic proteins, might also be influenced by regulating the abundance of active protein, which is modulated by the phosphorylation process as indicated by the downregulation of sma-miR5 in response to $\mathrm{NaCl}$ application (Fig. 5) and the presence of the target serine/threonine kinase family protein in $S$. maritima and both mangrove plants (Table 3). The importance of protein phosphorylation in salt tolerance has also been indicated by Feng et al. [27] in S. europaea.

The salt tolerance process in halophytes is mediated by many proteins in various ways $[3,27,68]$. Feng et al. [27] stressed the important roles of the proteins such as squamosa promoter-binding-like protein (SPL) and nuclear factor Y subunit A (NF-YA), among others, in the morphological adaptation of the halophyte S. europaea to salt stress, which also seems to hold true for S. maritima, because the miRNAs (sma-miR156b, -157d and -169g) targeting these transcripts (Additional file 11) were downregulated in response to $\mathrm{NaCl}$ (Fig. 2). Moreover, salt application downregulated the expression of miR-169g targeting NF-YA in the halophyte S. brachiata [31]. Feng et al. [27] further related salt tolerance in S. europaea to the increase in protein turnover that occurs as a result of the miRNA-regulated upregulation of the F-box protein. Salt application has also been reported to increase F-box protein transcripts in S. maritima and S. fruticosa [3, 68], and the increase in $S$. maritima could have been caused by the downregulation of certain miRNAs, such as sma-miR157d and sma-miR156b (Fig. 2), which target the mRNAs encoding F-box proteins (Additional file 11). These results suggest the important role of the ubiquitin/26S proteasome system in maintaining the required protein turnover demanded by the metabolic requirements in the presence of salt [27]. In addition, Sahu and Shaw et al. [3] indicated accumulation of glycinebetaine as an important component of salt tolerance in $S$. maritima, and the salt-induced downregulation of sma-miR169g (Fig. 2) supports the same because the miRNA targets phosphoethanolamine $\mathrm{N}$-methyltransferase (Additional file 11), which is involved in glycinebetaine biosynthesis. Nevertheless, the overall salt tolerance process in halophytes could be under the control of regulatory kinases $[27,68]$, a possibility that is also supported by the current study in which $\mathrm{NaCl}$ induced the downregulation of sma-miR157d and -miR5 (Figs. 2 and 5), which target serine-threonine kinase (Additional file 11, Table 3).

Although the regulatory role of miRNAs cannot be generalized, the expression of sma-miR2 and sma-miR5 only in plants growing in saline environments, such as $S$. maritima, S. portulacastrum, C. arenarius and I. pescaprae (Additional file 9), does suggest that these miRNAs might be regulating certain biochemical processes common in the plants that are important for their survival in the given saline ecological conditions. In this regard, it is important to note that sma-miR2 targets 4-coumarate-CoA ligase in S. maritima (Table 3), an enzyme that plays a pivotal role in the biosynthesis of plant secondary compounds with essential functions in plant development and environmental interactions [69].

\section{Conclusion}

This study identified 134 conserved and thirteen novel miRNAs in S. maritima, a halophyte. More importantly, the study demonstrated that the transcriptome of one species can be successfully used to computationally predict miRNAs in other species inhabiting similar environments, even if they are taxonomically distantly related. However, metabolism could be an even more important determining factor of similarity in miRNAomes of two species than the habitat. This study further revealed that a high ratio of known or conserved miRNAs to the number of families to which they belong could be considered a potential indicator of further miRNA identifications in a species, a result that is supported by the lack of identities among the novel miRNAs identified in the three halophytes, including S. brachiata [31], S. europaea [27] and S. maritima (this study). Furthermore, the responsiveness of many of the conserved miRNAs and most of the novel miRNAs in particular to salt suggested their important roles, in the metabolic adjustments to facilitate growth in a saline environment. However, any role for miRNAs in salt tolerance in halophytes may not be straightforward because several metabolic pathways could be acting either in parallel or in sequence during the process $[3,27,68]$. Of course, the miRNAs specifically expressed in plants growing under the influence of seawater, such as sma-miR2 and sma-miR5, could be important for the plants' survival in a saline environment. Although miRNA-mediated molecular mechanisms for salt tolerance in plants have yet to be established, the target prediction of novel miRNAs provided an indication that ubiquitin-mediated alterations in the abundance of plasma membrane and cytosolic proteins and phosphorylation-mediated alterations of their active states could be important miRNA-regulated biochemical processes for salt tolerance in halophytes. 


\section{Additional files}

Additional file 1: Taxonomy of the plant species used in the study. (DOCX $17 \mathrm{~kb}$ )

Additional file 2: Probes and primer sequences. (XLSX $262 \mathrm{~kb}$ )

Additional file 3: Summary of sRNA reads. (DOCX $17 \mathrm{~kb}$ )

Additional file 4: Pooled reads of the conserved miRNAs identified from the SRNA reads generated by sequencing of the sRNAs libraries and details of the precursors of the novel and conserved miRNAs validated experimentally for their presence in S. maritima. (XLSX $42 \mathrm{~kb}$ )

Additional file 5: Stem-loop secondary structure of precursors of the novel and conserved miRNAs validated experimentally for their presence in S. maritima. (PPT $4355 \mathrm{~kb}$ )

Additional file 6: Details of the precursors of the conserved miRNAs present in S. maritima and/or R. mangle. (DOCX $19 \mathrm{~kb}$ )

Additional file 7: Progress of the Stem-Loop PCR for the novel miRNAs in control and $\mathrm{NaCl}$ treated S. maritima and the rice cultivars, and in S. portulacastrum collected from its natural saline habitat. (PPTX $4 \mathrm{mb}$ )

Additional file 8: Changes in the relative electron transport rate (ETR) in the leaves of the test plants determined after their exposure to $255 \mathrm{mM} \mathrm{NaCl}$ (O. sativa cv. Badami/Pokkali) or $340 \mathrm{mM}$ $\mathrm{NaCl}$ (S. maritima) for $9 \mathrm{~h}, 24 \mathrm{~h}$ and $96 \mathrm{~h}$. (TIFF $8 \mathrm{mb}$ )

Additional file 9: Study of the expression of sma-miR2 and sma-miR5 in S. maritima, S. portulacastrum, C. arenarius and I. pes-caprae, which were collected from their natural ecological environments. (TIFF $20 \mathrm{~kb}$ )

Additional file 10: The target ESTs of the conserved miRNAs represented in Fig. 2. (DOCX $242 \mathrm{~kb}$ )

Additional file 11: Targets of the conserved miRNAs mentioned in Fig. 2. (DOC $283 \mathrm{~kb})$

\section{Competing interests}

The authors declare that they have no conflicts of interest and state that neither ILS nor DBT, who supported the work in terms of salaries, laboratory facilities and research grants, would lose or gain financially by the publication of this manuscript.

\section{Authors' contributions}

BPS conceived and coordinated the study. SAG conducted all of the experiments. BPS and SAG jointly analyzed the data and drafted the manuscript. BPS critically revised the manuscript for intellectual content. Both of the authors read and approved the final manuscript

\section{Acknowledgements}

The authors are thankful to the Director of the Institute of Life Sciences for providing laboratory facilities for this work. SAG is thankful to the Dept. of Biotechnology, New Delhi, for providing a fellowship. This work was financially supported by a DBT grant-in-aid to ILS. BPS is also thankful for an extramural grant from DBT: grant no. BT/PR-10975/AGR/02/619/2008. The miRNA data sequencing services provided by Sandor Proteomics, Hyderabad are also duly acknowledged. The authors are also thankful to Bionivid, Bangalore, India for allowing the limited use of their transcriptome data for S. maritima. The authors declare that they have no conflicts of interest.

Received: 24 June 2015 Accepted: 13 December 2015

Published online: 29 December 2015

\section{References}

1. Zhang Z, Wei L, Zou X, Tao Y, Liu Z, Zheng Y. Submergence-responsive MicroRNAs are potentially involved in the regulation of morphological and metabolic adaptations in maize root cells. Annals Bot. 2008;102:509-19.

2. Sahu BB, Shaw BP. Salt-inducible isoform of plasma membrane $H^{+}$ATPase gene in rice remains constitutively expressed in natural halophyte. Suaeda maritima J Plant Physiol. 2009;166:1077-89.
3. Sahu BB, Shaw BP. Isolation, identification and expression analysis of saltinduced genes in Suaeda maritima, a natural halophyte, using PCR-based suppression subtractive hybridization. BMC Plant Biol. 2009;9:69.

4. Zahaf O, Blanchet S, de Zélicourt A, Alunni B, Plet J, Laffont C, et al. Comparative transcriptomic analysis of salt adaptation in roots of contrasting Medicago truncatula genotypes. Mol Plant. 2012;5:1068-81.

5. Samuels M, Fire A, Sharp PA. Separation and characterization of factors mediating accurate transcription by RNA polymerase. J Biol Chem. 1982;257:14419-27.

6. Samuels M, Sharp PA. Purification and characterization of a specific RNA polymerase II transcription factor. J Biol Chem. 1986;261:2003-13.

7. Buratowski S, Hahn S, Guarente L, Sharp PA. Five intermediate complexes in transcription by RNA polymerase II. Cell. 1989;56:549-61.

8. Fire A, Xu SQ, Montgomery MK, Kostas SA, Driver SE, Mello CC. Potent and specific genetic interference by double-stranded RNA in Caenorhabditis elegans. Nature. 1998;391:806-11.

9. Schweizer P, Pokorny J, Schulze-Lefert P, Dudler R. Double-stranded RNA interferes with gene function at the single-cell level in cereals. Plant J. 2000;24:895-903.

10. Kim VN, Han J, Siomi MC. Biogenesis of small RNAs in animals. Nat Rev. 2009;10:126-39.

11. Phillips JR, Dalmay T, Bartels D. The role of small RNAs in abiotic stress. FEBS Lett. 2007:581:3592-7.

12. Axtell MJ. Classification and comparison of small RNAs from plants. Ann Rev Plant Biol. 2013;64:137-59.

13. Li YF, Zheng Y, Addo-Quaye C, Zhang L, Saini A, Jagadeeswaran G, et al. Transcriptome-wide identification of microRNA targets in rice. Plant J. 2010;62:742-59.

14. Zhang B, Wang Q. MicroRNA-based biotechnology for plant improvement. J Cell Physiol. 2015;230:1-15.

15. Shalgi R, Lieber D, Oren M, Pilpel Y. Global and local architecture of the mammalian microRNA-transcription factor regulatory network. PLoS Comput Biol. 2007;3, e131.

16. Sontheimer EJ, Carthew RW. Silencing from within: endogenous siRNAs and miRNAs. Cell. 2005;122:9-12.

17. Bao N, Lye K-W, Barton MK. MicroRNA binding sites in Arabidopsis class iii HD-zip mRNAs are required for methylation of the template chromosome. Dev Cell. 2004:7:653-62.

18. Kim DH, Saetrom P, Snøve Jr O, Rossi JJ. MicroRNA-directed transcriptional gene silencing in mammalian cells. Proc Natl Acad Sci. 2008;105:16230-5.

19. Place RF, Li L-C, Pookot D, Noonan EJ, Dahiya R. MicroRNA-373 induces expression of genes with complementary promoter sequences. Proc Natl Acad Sci. 2008;105:1608-13.

20. Huang V, Place RF, Portnoy V, Wang J, Qi Z, Jia Z, et al. Upregulation of Cyclin B1 by miRNA and its implications in cancer. Nucleic Acids Res. 2012;40:1695-707.

21. Vasudevan S, Steitz JA. AU-Rich-element-mediated upregulation of translation by FXR1 and argonaute 2. Cell. 2007:128:1105-8

22. Vasudevan S, Tong Y, Steitz JA. Switching from repression to activation: microRNAs can upregulate translation. Science. 2007;318:1931-4.

23. Orom UA, Nielsen FC, Lund AH. MicroRNA-10a binds the $5^{\prime}$ UTR of ribosomal protein mRNAs and enhances their translation. Mol Cell. 2008:30:460-71.

24. Ding D, Zhang L, Wang H, Liu Z, Zhang Z, Zheng Y. Differential expression of miRNAs in response to salt stress in maize roots. Annals Bot. 2009:103:29-38.

25. Macovei A, Tuteja N. microRNAs targeting DEAD-box helicases are involved in salinity stress response in rice (Oryza sativa L.). BMC Plant Biol. 2012;12:183.

26. Sunkar R, Li YF, Jagadeeswaran G. Functions of microRNAs in plant stress responses. Trends Plant Sci. 2012;17:196-203.

27. Feng J, Wang J, Fan P, Jia W, Nie L, Jiang P, et al. High-throughput deep sequencing reveals that microRNAs play important roles in salt tolerance of euhalophyte Salicornia europaea. BMC Plant Biol. 2015;15:63.

28. Sunkar R, Zhu JK. Novel and stress-regulated microRNAs and other small RNAs from Arabidopsis. Plant Cell. 2004;16:2001-19.

29. Katiyar-Agarwal S, Gao S, Vivian-Smith A, Jin H. A novel class of bacteriainduced small RNAs in Arabidopsis. Genes Dev. 2007;21:3123-34.

30. Khraiwesh B, Pugalenthi G, Fedoroff NV. Identification and analysis of red sea mangrove (Avicennia marina) microRNAs by high-throughput sequencing and their association with stress responses. PLoS One. 2013;8, e60774. 
31. Singh $D$, Jha $B$. The isolation and identification of salt-responsive novel microRNAs from Salicornia brachiata, an extreme halophyte. Plant Biotechnol Rep. 2014;8:325-36.

32. Zhu J, Li W, Yang W, Qi L, Han S. Identification of microRNAs in Caragana intermedia by high-throughput sequencing and expression analysis of 12 microRNAs and their targets under salt stress. Plant Cell Rep. 2013;32:1339-49.

33. Jovanovic Z, Stanisavljevic N, Mikic A, Radovic S, Maksimovic V. Water deficit down-regulates miR398 and miR408 in pea (Pisum sativum L.). Plant Physiol Biochem. 2014;83:26-31

34. Wang B, Sun YF, Song N, Wei JP, Wang XJ, Feng $H$, et al. MicroRNAs involving in cold, wounding and salt stresses in Triticum aestivum L. Plant Physiol Biochem. 2014;80:90-6.

35. Kozomara A, Griffiths-Jones S. miRBase: annotating high confidence microRNAs using deep sequencing data. Nucleic Acids Res. 2014;42:D68-73.

36. Yi X, Zhang Z, Ling Y, Xu W, Su Z. PNRD: a plant non-coding RNA database. Nucleic Acids Res. 2015;43:D982-9.

37. Flowers TJ. Salt tolerance in Suaeda maritima (L.) Dum. J Exp Bot. 1972;23:310-21.

38. Wang S-M, Zhang J-L, Flowers TJ. Low-affinity $\mathrm{Na}^{+}$uptake in the halophytes Suaeda maritima. Plant Physiol. 2007;145:559-71.

39. Flowers TJ, Colmer TD. Salinity tolerance in halophytes. New Phytol. 2008;179:945-63.

40. Mallik S, Nayak S, Sahu BB, Panigrahi AK, Shaw BP. Response of antioxidant enzymes to high $\mathrm{NaCl}$ concentration in different salt-tolerant plants. Biol Plant. 2011:55:191-5.

41. Mohamed E, Matsuda R, El-khatib AA, Takechi K, Takano H, Takio S. Characterization of the superoxide dismutase genes of the halophyte Suaeda maritima in Japan and Egypt. Plant Cell Rep. 2015. doi:10.1007/ s00299-015-1854-1.

42. Sahu BB. Biochemical and molecular characterization of $\mathrm{H}^{+}$ATPase in plants differing in salt tolerance, Ph.D. thesis. Utkal University: Department of Botany; 2009 .

43. Sengupta S, Majumder AL. Insight into the salt tolerance factors of a wild halophytic rice, Porteresia coarctata: a physiological and proteomic approach. Planta. 2009;229:911-29.

44. Maxwell K, Johnson GN. Chlorophyll fluorescence-a practical guide. J Exp Bot. 2000;51:659-68.

45. Zuker M. Mfold web server for nucleic acid folding and hybridization prediction. Nucleic Acids Res. 2003;31:3406-15.

46. Meyers BC, Axtell MJ, Bartel B, Bartel DP, Baulcombe D, Bowman JL, et al Criteria for annotation of plant microRNAs. Plant Cell. 2008;20:3186-90.

47. Wan L-C, Wang F, Cuo X, Lu S, Qui Z, Zhao Y, et al. Identification and characterization of small non-coding RNAs from Chinese fir by high throughput sequencing. BMC Plant Biol. 2012;12:146.

48. Chen C, Ridzon DA, Broomer AJ, Zhou Z, Lee DH, Nguyen JT, et al. Realtime quantification of microRNAs by stem-loop RT-PCR. Nucleic Acids Res. 2005;33, e179.

49. Livak KJ, Schmittgen TD. Analysis of relative gene expression data using real-time quantitative PCR and the 2(-Delta Delta C(T)) Method. Methods. 2001;25:402-8

50. Bliss Cl. Statistics in Biology, Statistical methods for research in natural sciences. Vol. 1. New York: McGraw-Hill Book Company; 1967

51. Dai $X$, Zhao PX. psRNATarget: a plant small RNA target analysis server. Nucleic Acids Res. 2011;39:W155-9.

52. Song C, Wang C, Zhang C, Korir NK, Yu H, Ma Z, et al. Deep sequencing discovery of novel and conserved microRNAs in trifoliate orange (Citrus trifoliata). BMC Genomics. 2010;11:431.

53. Mao W, Li Z, Xia X, Li Y, Yu J. A combined approach of high-throughput sequencing and degradome analysis reveals tissue specific expression of microRNAs and their targets in cucumber. PLoS One. 2012;7, e33040.

54. Xu MY, Dong Y, Zhang QX, Zhang L, Luo YZ, Sun J, et al. Identification of miRNAs and their targets from Brassica napus by high-throughput sequencing and degradome analysis. BMC Genomics. 2012;13:421.

55. Zhang R, Marshall D, Bryan GJ, Hornyik C. Identification and characterization of miRNA transcriptome in potato by high-throughput sequencing. PLoS One. 2013;8, e57233.

56. Liu P, Yan K, Lei YX, Xu R, Zhang YM, Yang GD, et al. Transcript profiling of microRNAs during the early development of the maize brace root via Solexa sequencing. Genomics. 2013;101:149-56.
57. Ren Y, Chen L, Zhang Y, Kang X, Zhang Z, Wang Y. Identification and characterization of salt-responsive microRNAs in Populus tomentosa by high-throughput sequencing. Biochim. 2013;95:743-50.

58. Sunkar R, Zhou X, Zheng Y, Zhang W, Zhu JK. Identification of novel and candidate miRNAs in rice by high throughput sequencing. BMC Plant Biol. 2008:8:25.

59. Dassanayake M, Haas JS, Bohnert HJ, Cheeseman JM. Shedding light on an extremophile lifestyle through transcriptomics. New Phytol. 2009;183:764-75.

60. De Paola D, Cattonaro F, Pignone D, Sonnante G. The miRNAome of globe artichoke: conserved and novel micro RNAs and target analysis. BMC Genomics. 2012;13:41.

61. Sciorra VA, Morris AJ. Roles for lipid phosphate phosphatases in regulation of cellular signaling. Biochim Biophys Acta. 2002;1582:45-51.

62. Glickman $\mathrm{MH}$, Cienchanover A. The ubiquitin-proteasome proteolytic pathway: destruction for the sake of construction. Physiol Rev. 2002;82:373-428.

63. Stone SL. The role of ubiquitin and the $26 \mathrm{~S}$ proteasome in plant abiotic stress signaling. Front Plant Sci. 2014;5:135.

64. Kuroda H, Takahashi N, Shimada H, Seki M, Shinozaki K, Matsui M. Classification and expression analysis of Arabidopsis F-box-containing protein genes. Plant Cell Physiol. 2002;43:1073-85.

65. Javid MG, Sorooshzadeh A, Moradi F, Sanavy SAMM, Allahdadi I. The role of phytohormones in alleviating salt stress in crop plants. Aust J Crop Sci. 2011;5:726-34

66. Bao F, Azhakanandam S, Franks RG. SEUSS and SEUSS-LIKE transcriptional adaptors regulate floral and embryonic development in Arabidopsis. Plant Physiol. 2010;152:821-36.

67. Scheuring D, Kunzl F, Viotti C, Yan MS, Jiang L, Schellmann S, et al. Ubiquitin initiates sorting of Golgi and plasma membrane proteins into the vacuolar degradation pathway. BMC Plant Biol. 2012;12:164.

68. Diray-Arce J, Clement M, Gul B, Khan MA, Nielsen BL. Transcriptome assembly, profiling and differential gene expression analysis of the halophyte Suaeda fruticosa provides insights into salt tolerance. BMC Genomics. 2015;16:353.

69. Hamberger B, Hahlbrock K. The 4-coumarate:CoA ligase gene family in Arabidopsis thaliana comprises one rare, sinapate-activating and three commonly occurring isoenzymes. Proc Natl Acad Sci. 2004;101:2209-14.

70. Kulcheski FR, de Oliveira LF, Molina LG, Almerao MP, Rodrigues FA, Marcolino J, et al. Identification of novel soybean microRNAs involved in abiotic and biotic stresses. BMC Genomics. 2011;12:307.

71. Paul S, Kundu A, Pal A. Identification and validation of conserved microRNAs along with their differential expression in roots of Vigna unguiculata grown under salt stress. Plant Cell Tiss Organ Cult. 2011;105:233-42.

72. Lu S, Sun YH, Shi R, Clark C, Li L, Chiang VL. Novel and mechanical stressresponsive MicroRNAs in Populus trichocarpa that are absent from Arabidopsis. Plant Cell. 2005;17:2186-203.

73. Arenas-Huertero C, Perez B, Rabanal F, Blanco-Melo D, De la Rosa C, EstradaNavarrete $\mathrm{G}$, et al. Conserved and novel miRNAs in the legume Phaseolus vulgaris in response to stress. Plant Mol Biol. 2009;70:385-401.

74. Bertolini E, Verelst W, Horner DS, Gianfranceschi L, Piccolo V, Inze D, et al. Addressing the role of microRNAs in reprogramming leaf growth during drought stress in Brachypodium distachyon. Mol Plant. 2013;6:423-43.

75. Kantar M, Unver T, Budak H. Regulation of barley miRNAs upon dehydration stress correlated with target gene expression. Funct Integr Genomics. 2010;10:493-507.

76. Wu B, Li Y, Yan H, Ma Y, Luo H, Yuan L, et al. Comprehensive transcriptome analysis reveals novel genes involved in cardiac glycoside biosynthesis and mlncRNAs associated with secondary metabolism and stress response in Digitalis purpurea. BMC Genomics. 2012;13:15.

77. Jones-Rhoades MW, Bartel DP. Computational identification of plant microRNAs and their targets, including a stress-induced miRNA. Mol Cell. 2004:14:787-99. 